\title{
A Conditional Intent to Perform
}

Gregory Klass

Georgetown University Law Center, gmk9@law.georgetown.edu

Georgetown Public Law and Legal Theory Research Paper No. 09-08

This paper can be downloaded free of charge from:

https://scholarship.law.georgetown.edu/facpub/604

http://ssrn.com/abstract=1364456

15 Legal Theory 107-147 (2009)

This open-access article is brought to you by the Georgetown Law Library. Posted with permission of the author. Follow this and additional works at: https://scholarship.law.georgetown.edu/facpub

Part of the Contracts Commons 
Legal Theory, 15 (2009), 107-147. Printed in the United States of America

(C) 2009 Cambridge University Press 0361-6843/09 \$15.00+ 00

doi:10.1017/S1352325209090089

\title{
A CONDITIONAL INTENT TO PERFORM
}

\author{
Gregory Klass* \\ Georgetown University Law Center
}

The doctrine of promissory fraud holds that a contractual promise implicitly represents an intent to perform. A promisor's conditional intent to perform poses a problem for that doctrine. It is clear that some undisclosed conditions on the promisor's intent should result in liability for promissory fraud. Yet no promisor intends to perform come what may, so there is a sense in which all promisors conditionally intend to perform.

Building on Michael Bratman's planning theory of intentions, this article provides a theoretical account of the distinction between "foreground" and "background" conditions on intentions in general and then explains why foreground conditions on a promisor's intent to perform are likely to result in material promissory misrepresentation, while background conditions are not. The difference between foreground and background conditions lies in whether the agent accepts the satisfaction of the condition for the purposes of her practical reasoning. A promisor's nonacceptance of a condition on her intent to perform is material because it is likely to affect her preperformance deliberations and investment in the transaction, as well as her willingness to seek agreement with the promisee on how to fill contractual gaps.

There seems an obvious difference between conditional and unconditional intentions. Consider the two reports "I intend to go to the faculty meeting" and "I intend to go to the faculty meeting if I finish preparing my class." The first says that I simply mean to be there; the second that I mean be there in some possible futures and not in others. But perhaps the difference is only apparent. While my report that I intend simpliciter to go to the meeting does not describe my intention as conditional, it would be silly to understand me as saying that I mean to go no matter what. I do not intend to go if the meeting is cancelled. Nor do I expect to go if something more important comes up. I intend to go to the meeting ceteris paribus: unless something occurs to prevent me or to cause me to reconsider. A bit of reflection suggests that one never intends to do something come what

\footnotetext{
*This article has benefited from the input of Michael Bratman, Luca Ferrero, David Owens, and Gideon Yaffe as well as anonymous referees from LeGAL Theory. My thanks to all, and to Addison Draper and Gregory Zlotnick for their research assistance and Ian Ayres for our earlier collaboration.
}

\section{CAmbridge JDURNALS}

http://journals.cambridge.org 
may-that all intentions are subject to innumerable implicit ceteris paribus conditions. And now it looks as though the difference between the two cases lies not in the intention itself but in the way I describe it. While a report "I intend $x$ if C" provides more information about when the speaker is likely to $x$, the attitude it reports is not different in kind from a nominally unconditional intention.

The slipperiness in the distinction between conditional and unconditional intentions creates a puzzle in a corner of contract theory. According to the doctrine of promissory fraud, a contractual promise implicitly represents a present intent to perform. To make a promise one intends to breach is to tell a lie. A plaintiff who can prove promissory fraud can recover not only compensatory damages for the breach but also punitive damages; in some cases an insincere promisor can even face criminal penalties. The puzzle is whether an undisclosed condition on the promisor's intent to perform should result in liability for promissory fraud.

Consider the facts in Hillcrest Center, Inc. v. Rone, in which the owner of a commercial building told a tenant that she intended to purchase an adjacent lot to provide parking for the tenant. ${ }^{1}$ The Alabama Supreme Court upheld a jury finding of fraud based on evidence that the defendant "never intended to purchase the adjacent lot to provide the additional parking unless she was able to secure a tenant for the proposed building to be built on the adjacent lot (a 'contingency' [the owner] never communicated to the [tenant])." ${ }^{2}$ The holding feels right: the defendant represented that she intended to purchase the lot, not that she intended to purchase it only if certain conditions were satisfied. But if this is correct, we need to be able to say why this condition on the defendant's intent resulted in a material misrepresentation while the ceteris paribus conditions that attach to all intentions do not.

In our book, Insincere Promises: The Law of Misrepresented Intent, Ian Ayres and I suggest that the difference involves informational disparities. ${ }^{3}$ If every representation of an unconditional intention includes an implicit ceteris paribus clause, then the competent hearer is on notice that the speaker's intention is so conditioned. And because parties enter into agreements with a shared background understanding as to what might cause the promisor to choose not to perform or prevent her from doing so, they have a shared understanding of the extension of that implicit ceteris paribus-of what counts as "other things being equal." Neither of the Hillcrest parties would have expected the defendant to purchase the adjacent lot if it were destroyed by flood or even if its price suddenly skyrocketed (though in the latter case, the defendant might still be liable for breach of a promise to

1. Hillcrest Center, Inc. v. Rone, 711 So. 2d 901, 903 (Ala. 1997).

2. Id. at 906 .

3. Ian Ayres \& Gregory Klass, Insincere Promises: The LaW of Misrepresented Intent 26-29 (2005).

\section{CAMBridge}

http://journals.cambridge.org 
purchase). This explains the court's emphasis on the fact that the defendant "never communicated" that her intent to purchase was conditioned on finding a tenant for the property. Because that condition fell outside the mutually understood scope of the implicit ceteris paribus, it rendered false the defendant's representation that she intended to perform.

This information-based account was of a piece with our project in Insincere Promises: to develop a theory of promisor representations of intent, not of promisor intentions per se. For this reason, however, the explanation is incomplete. There is a strong intuition that there is an intrinsic difference between the implicit ceteris paribus conditions that attach to all intentions and more salient conditions on a person's intent such as the undisclosed condition in Hillcrest - a difference not only in what is known about the conditions but between ways that intentions are conditional. This article argues that this intuition is correct. The goal is to provide a theory of the intuitive distinction between what I henceforth call "background" and "foreground" conditions and to explain the relation of each to the law of promissory fraud.

My account of the distinction builds on Michael Bratman's planning theory of intention. ${ }^{4}$ In our book, Ayres and I write that a "promisor's intention to perform is material only because it entails her being likely to perform, only because it provides the promisee crucial information for evaluating [the probability of performance]." 5 This claim focuses on the fact that intentions tend to cause persons who have them to do the acts intended. ${ }^{6}$ A person's intention to $x$ makes it more likely that she will $x$. Standing alone, this is a fairly anemic picture of future-directed intentions. In it, a future-directed intention operates something like a billiard ball: once put in motion, the intention rolls along in a straight line without disturbing the rest of the table until it reaches its target, unless it is knocked off course by unanticipated circumstances or the player changes her mind and grabs it mid-course. Bratman's planning theory argues that things are more complex. A person's future-directed intentions not only cause her to do the intended act but shape her practical deliberations and behavior leading up to that point in a way that ensures the coherence and effectiveness of her practical attitudes as a whole. This is what it means to have an intention. On Bratman's theory, the billiard ball on the way to its target interacts with the table as a whole in a way that both increases the chances it will reach the target and organizes the other balls in light of the shot.

This theory allows for a more complete description of the difference between background and foreground conditions on an agent's intention. The difference lies in the consequences of each for the agent's practical deliberations. A person's intention is background-conditional when she

4. This is laid out in Michael E. Bratman, Intention, Plans, and Practical Reason (1987).

5. AYres \& KLASS, supra note 3, at 35.

6. I use "cause" here in the broadest sense possible. I mean to suggest nothing about the sort of causal mechanisms at work.

\section{CAMBRIDGE}

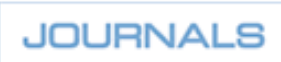

http://journals.cambridge.org 
assumes for the purpose of her practical deliberations that the condition will or that it will not be satisfied. Her intention is foreground-conditional when she treats the satisfaction of the condition as an open question. Foreground conditions on an agent's intention have two important consequences for her ongoing deliberation and behavior: they permit her to plan rationally for more possible futures, including futures in which she does not perform the act in question, and they reduce the rational pressure on her to intend the necessary means of acting.

This theory suggests three reasons why a promisee should care more about a foreground condition than a background condition on the promisor's intent to perform. First, foreground conditions are likely to affect the promisor's preperformance practical deliberations and investments in the transaction in a way that further decreases the likelihood of performance. Second, the promisor herself has made a (perhaps reflexive) judgment that the chance the condition will not be satisfied is high enough to warrant taking it into account in her own deliberations-prima facie evidence that the promisee would also do well to consider that possibility. Finally, in relational contracts a foreground condition on the promisor's intent to perform reduces the rational pressure to fill contract gaps in a way that agrees with the plans and preferences of the promisee. These conclusions suggest a new account of what, if anything, a promise implicitly represents about any conditions on the promisor's intent to perform. They also answer Aditi Bagchi's and Richard Craswell's suggestions that, from the consequentialist perspective Ayres and I adopt, the legal question should be not the promisor's intent to perform but only the probability of performance. ${ }^{7}$

After I describe the shortcomings of two other theories of background and foreground intentions in Section I of this article, Section II lays out the analytic groundwork for a planning theory of conditional intentions, which I then develop in Section III. This general theory provides the basis for Section IV's reexamination of the legal relevance of a conditional intent to perform. Readers interested only in the theory of intentions might skip Section IV; readers whose primary interest is in contract law might skip Section I, read only the summary of Section III, and focus their attention on Section IV.

The analysis in this article has benefited from two recent works of conditional intentions. Gideon Yaffe applies Bratman's planning theory of intentions to provide a new analysis of how conditional intentions should figure into criminal mens rea inquiries. ${ }^{8}$ While my account relies on some of his insights, Yaffe does not tackle the problem of this article: the difference

7. Aditi Bagchi, The Accidental Promise: Remaking the Law of Misrepresented Intent, $2008 \mathrm{U}$. ILL. L. Rev. 985 (reviewing Ayres \& KLASS, supra note 3); Richard Craswell, Taking Information Seriously: Misrepresentation and Nondisclosure in Contract Law and Elsewhere, 92 VA. L. Rev. 565 (2006).

8. Gideon Yaffe, Conditional Intent and Mens Rea, 10 Legal Theory 273 (2004).

\section{CAMBRIDGE}

http://journals.cambridge.org 
between background and foreground conditions. ${ }^{9}$ Luca Ferrero applies Bratman's planning theory to provide a more general account of conditional intentions. ${ }^{10}$ Ferrero's analysis of the difference between background and foreground conditions parallels one of my central claims: that background conditions are conditions that the agent accepts in her practical deliberations. Our analyses of the structure of conditional intentions, however, are different. For example, where Ferrero argues against a truth-functional reading of intended conditions, I argue for that reading, at least with respect to consequences for the agent's practical deliberations. This allows me to identify and examine a broader range of conditional intentions.

The doctrinal consequences of this analysis are not earth-shattering. If promissory fraud is but one room in the house of contract law, claims based on a conditional intent to perform are something like a knickknack on the mantle. Nor does this article recommend doctrinal reform; the project is purely analytic. But just as the existence and function of the law of promissory fraud illuminate the structure and purpose of contract law as a whole, so, too, the correct analysis of conditional intentions to perform casts new light on contractual relationships more generally. In many instances, contracting parties agree not only to perform, or to perform or pay damages; they agree to enter into a shared project that assumes flexibility and mutual responsiveness. Partly because of this, contractual obligations often do not map onto everything to which the parties have agreed. There are reasons to think that this is a good thing, despite the claims of many first-generation relational-contract theorists. ${ }^{11}$ It does not follow, however, that the law as a whole-and especially the law of fraud-is or should be indifferent to the complexity of the extralegal relationships between contracting parties. Nor should contract theory ignore it. The proper legal attitude toward the extralegal, relationship-based expectations and obligations that come with agreements for consideration is a central question for contract theory. The doctrine of promissory fraud, the puzzle of conditional intentions to perform, and Bratman's planning theory of intention together provide the beginnings of a more nuanced account of those expectations and obligations and of the law's proper response to them.

9. Yaffe does not need to, for he argues that the line for criminal liability cuts across that distinction. $I d$. at $290-298$.

10. Luca Ferrero, Conditional Intentions, Noûs (forthcoming) (references are to paragraph numbers in version 2.5 , Nov. 30,2008 , on file with the author). I am especially grateful for Ferrero's permission to cite and discuss a paper that he is still in the process of revising. It might turn out that some of my comments or criticisms do not apply to the published version of Ferrero's article. If so, they should be read as snippets from the middle of a conversation-one from which I have greatly benefited.

11. See, e.g., Robert E. Scott, The Case for Formalism in Relational Contracts, 94 Nw. U. L. REv. 847 (2000). For an overview, see Dori Kimel, The Choice of Paradigm for Theory of Contract: Reflections on the Relational Model, 27 OXford J. LEGAL STUD. 233, 238, 250-253 (2007).

\section{CAMBRIDGE}

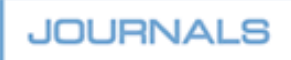

http://journals.cambridge.org 


\section{THE AWARENESS THEORY AND THE REASON THEORY}

The intuitive distinction between background and foreground conditions on a person's intention is reflected in how we describe the effect of changed circumstances. Suppose Jones owns a successful coffee shop and learns that the store next door is going to be vacated. Jones has been thinking about expanding, so she enters into a contract with the owner of the neighboring building to purchase it in six months. Jones does not, however, have the funds to renovate the space, and she has had some credit problems. Knowing all this, Jones forms a conditional intent that she will purchase the building only if she secures a construction loan. If Jones does not get the loan and then chooses not to purchase, we would not say that she has changed her mind. The situation would be different if Jones decided not to purchase because she subsequently learned that a Starbucks was opening across the street. Here we are more likely to say that an unanticipated change in circumstances caused Jones to change her mind. And this is so despite the fact that Jones knew from the beginning - in the sense that she would have said so if asked - that a Starbucks across the street would cause her to rethink expanding.

This intuitive distinction between foreground and background conditions is the target of my analysis. This section describes and criticizes two theories of it. The awareness theory argues that foreground conditions on a person's intention are those conditions she is conscious of. The reason theory maintains that foreground conditions are those whose satisfaction is a reason for or whose nonsatisfaction is a reason against doing the intended act. Describing the shortcomings of each theory sets the stage for the planning theory developed in Sections II and III.

The awareness theory holds that the difference between background and foreground conditions lies in the agent's awareness of the condition. Kenneth Campbell provides the following argument:

[A]ll intentions seem to involve a degree of self-awareness. I do not believe that it is possible to form an intention to do something and, at least at the period of formation of the intention, be unaware of what it is that one intends to do. And if this is true of the action it seems to be none the less true of the conditions to which performance of the action is, in one's intention, subject. So I do not see how an intention can have as part of its content a condition which had not occurred to one. ${ }^{12}$

12. Kenneth Campbell, Conditional Intention, 2 LEGAL STUd. 77, 89-90 (1982). Jack Meiland similarly argues that if an agent does not realize that the nonoccurrence of condition $C$ would affect his decision to $X$, " $C$ does not enter into his intention at all, although $C$ might become part of his intention if he realized that $C$ was relevant to the doing of $X$ or to his other purposes." Jack W. Meiland, The Nature of Intention 20 (1970).

\section{CAMBRIDGE}

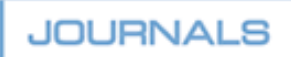

http://journals.cambridge.org 
On the awareness theory, whether a condition is foreground or background depends in part on whether the agent happened to consider it. If, when Jones enters into the contract to purchase the neighboring building, it occurs to her that Starbucks might open a store nearby and that she would then choose not to expand, the absence of a new Starbucks is a foreground condition of her intent to purchase. If she does not happen to consider that possibility, her intention is at most background-conditional with respect to a Starbucks opening.

Now, one response to Campbell's argument is to question its major premise-that persons are necessarily aware of the content of their intentions. Bratman argues, for example, that an agent can be mistaken about the details of what she intends. ${ }^{13}$ The deeper problem with the awareness theory, however, lies in the underlying conception of what intentions are.

Suppose Jones unconditionally intends to perform the contract to purchase the building adjacent to her coffee shop. If asked, she would admit that if someone offered her a million dollars to realize her dream of opening a skydiving school, she would take it and breach the contract to purchase. ${ }^{14}$ On the awareness theory, so long as the possibility of a million-dollar offer does not occur to Jones, she can unconditionally intend to purchase the building, but if it does occur to her, her intention is then conditional. This is true no matter how unlikely she thinks such an offer and whether or not her awareness of that possibility influences her practical deliberations or behavior. In fact, consideration of the million-dollar-offer hypothetical would influence neither. It is practically inert.

We are touching here on a bigger issue: what a theory of intentions is meant to explain. Certainly there is a difference between an agent who has reflected on the background conditions of her intention and one who has not. But if that reflection does not affect her practical deliberations or subsequent actions, it belongs to the domain of theoretical, not practical, reason. ${ }^{15}$ If there is a difference between background and foreground conditions, we should expect it to be manifest in the role each plays in an agent's practical life. The awareness theory points to a difference that does not make the right sort of difference.

J.P.W. Cartwright advocates another approach. Cartwright maintains that a foreground condition is a condition "such that its fulfillment constitutes

13. Michael E. Bratman, Intention, Belief, Practical, Theoretical, in Spheres of Reason (J. Timmerman et al. eds., forthcoming) (Sept. 22, $2008 \mathrm{draft}$ ) §4, at 12-13, available at http://philosophy.stanford.edu/download/18446/Bratman_IBPT_2008_final.pdf.

14. I ask the reader for the sake of the example to grant me that Jones would not be able to buy her way out of the sales contract.

15. Bratman discusses the difference between intending and having a belief about one's intentions in Michael E. Bratman, Cognitivism about Practical Reason, 102 Ethics 117 (1991), reprinted in Faces of INTENTION: Selected ARTicles on INTENTION ANd Agency 250 (1999), and in Bratman, Intention, Belief, supra note 13. The difference between intending and ascribing an intention to oneself is also central to Wilfrid Sellars's work on intentions. See, e.g., Wilfrid Sellars, On Reasoning about Values, 17 AM. PHIL. Q. 81, 84 (1980).

\section{CAMBridge}

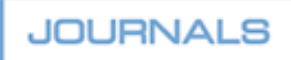

http://journals.cambridge.org 
a reason for continuing with the intention and performing the action intended, while its non-fulfillment constitutes a reason for not doing these things." 16 Cartwright then argues that what we intuitively take to be background conditions do not satisfy that criterion. He considers first the generic qualification "if nothing prevents me." Neither the satisfaction nor the nonsatisfaction of such a condition, Cartwright argues, provides the agent with a reason for or against doing the intended act. "An agent's belief in his capacity to $\varnothing$ cannot be said to be amongst his reasons for $\varnothing$ ing because it is, rather, the necessary background against which talk of reasons for and against Øing can take place."17 Cartwright reaches the same conclusion for "if nothing significant alters":

But... "if nothing significant alters" amounts in effect to "if I don't change my mind." Now "if I don't change my mind" is once again not a genuine condition by the test stated earlier. My not changing my mind cannot be said to be a reason for not continuing with the intention, since it just is identical with discontinuing the intention. ${ }^{18}$

Cartwright concludes that background conditions are not genuine conditions: "The fact that the change of mind is eminently predictable, instantaneous and requires no weighing of pros and cons, may cause it to resemble the automatic operation of a canceling condition, but the resemblance is deceptive. It remains for all this a change of mind." 19

There are several problems with this argument. To get at them, I need to highlight a distinction implicit in it that will also figure into my own analysis. An intention might be conditional because the agent has chosen to act only under certain circumstances or because the agent believes that only under certain circumstances will she be able to act on it. ${ }^{20}$ Jones's intention to purchase only if she can obtain a construction loan is of the first sort: she could buy the property without the construction loan-and then not renovate it-but she would not want to. Alternatively, suppose Jones learns that the city is considering condemning the building to take it for a public use. Jones's intent to purchase only if the building is not condemned is of the

16. J.P.W. Cartwright, Conditional Intention, 60 PHIL. STUD. 233, 240 (1990). Donald Davidson makes a similar suggestion:

[B] ona fide conditions are ones that are reasons for acting that are contemporary with the intention.... Changing his mind is a tricky case, but in general someone is not apt to view a possible future change of intention as a reason to modify his present intention unless he thinks the future change will itself be brought about by something he would now consider a reason.

Donald Davidson, Intending, in Essays on ACTIONS ANd Events 83, 94-95 (1980).

17. Cartwright, supra note 16, at 240.

18. Id. at 241-242.

19. Id. at 242 .

20. This is a first, rough take on the distinction. For a more nuanced description of it, see Section II.B.

\section{CAMBRIDGE}

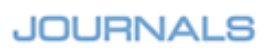

http://journals.cambridge.org 
second sort: condemnation would prevent her purchase. I will call chosen conditions "elective" and conditions on a person's ability to act "enabling" conditions. $^{21}$

The first difficulty with Cartwright's argument is that his analysis of background enabling conditions applies pari passu to what we normally consider foreground conditions. Suppose, again, that Jones intends to buy the building only if it is not condemned. No condemnation would not be a new reason to purchase the building. Nor would condemnation be a reason not to buy-it would simply prevent her from doing so. ${ }^{22}$ This is so no matter how much Jones attends to the possibility or takes it into account in her planning-no matter how much she thinks of her intent as conditional. If Cartwright's theory is correct, there are no foreground enabling conditions.

While perhaps unintuitive, that result is not necessarily wrong. The surface similarity between our descriptions of enabling and elective conditions might mask deeper differences, differences that should cause us on reflection to say that such conditions are different in kind. If so, perhaps there is a sense in which elective conditions can be "foreground" or "background" that does not apply to enabling conditions.

But the reason theory also fails to distinguish foreground elective conditions from background ones. Cartwright equates "if nothing significant alters" with "if I don't change my mind" to conclude that the former is not a reason for acting. But these are different propositions. If I am fickle or self-doubting, I might change my mind even if there has been no relevant change in circumstances. And the qualifier "significant" in "if nothing significant alters" appears designed to pick out just those changed circumstances that would give me a reason not to act. The better analysis of "I intend to $x$ if nothing significant alters" is along the lines of Ferrero's:

$$
\text { I intend [given } \mathrm{C}_{1}, \mathrm{C}_{2} \ldots \text {, to } x \text { ], }
$$

where " $\mathrm{C}_{1}, \mathrm{C}_{2} \ldots$ " stands for an as-yet-undetermined list of eventualities, the nonoccurrence of which would cause the agent to reconsider xing. ${ }^{23}$ On this analysis, "if nothing significant alters" does refer to reasons, though it does not yet specify what they are. The reason theory cannot distinguish such elective background conditions from elective foreground conditions.

21. Ferrero notes the distinction as well. Ferrero, supra note 10, ๆ 2 2.2-2.4. While he also uses the term "enabling conditions," Ferrero calls "restrictive conditions" what I designate "elective conditions."

22. Ferrero suggests that " $[\mathrm{t}]$ here is a perfectly acceptable sense in which the satisfaction of an enabling condition counts as a reason in support of the intended action." Id. $\uparrow 2.4$. If so, this is a rather attenuated sense as compared to elective conditions.

23. Compare Ferrero's (DS-E). Id. ฯ

\section{CAMbridge}

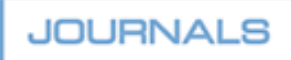

http://journals.cambridge.org 
Finally, and more generally, a person might elect to act on a condition, though satisfaction of the condition is not among her reasons for so acting nor its nonsatisfaction a reason for not acting. ${ }^{24}$ Mark Bittman, a food columnist for the New York Times, reports that he has a policy of eating "vegan until six." ${ }^{25}$ In other words, Bittman has a standing intention to eat no animal products, subject to a foreground elective condition: that it is before 6 P.M. Satisfaction of the condition-the fact that it is not yet sixhas nothing to do with Bittman's reasons for not eating animal products. Those reasons involve considerations of health and concerns for the environment. The reason for the condition has to do with Bittman's desire for a moderate plan he will stick to. While Bittman has reasons for adopting the conditional intention, the condition itself is not a reason for the intended act.

The point here touches on themes more fully explored in the next section's discussion of Bratman's planning theory. But the central claim can be stated now: intentions are not reasons but are "framework reasons." The difference lies in the fact that intentions "do not compete with desire-belief reasons, but rather structure the process of weighing such reasons." ${ }^{26}$ This is the more fundamental reason to reject Cartwright's reason theory.

Both the awareness theory and the reason theory point to real differences among conditional intentions. Agents sometimes do and sometimes do not attend to the conditions on their intentions, and some conditions are more closely tied to an agent's reasons for acting than are others. But neither distinction marks the right sort of a difference in how an agent's intentions figure into her cognitive economy. Neither captures the intuitive difference between foreground and background conditions. Section III argues that a planning theory does.

\section{GROUNDWORK FOR THE PLANNING THEORY}

A more satisfactory account of the difference between background and foreground conditions on a person's intention requires some preliminary analytic spadework. First, I need to describe a few pieces of Bratman's theory of intention, which are deployed in Section III to explain the difference between background and foreground conditions. Second, it is important to differentiate between three types of intended conditions: necessary, sufficient, and necessary and sufficient. One might intend to act on any of these types of conditions, depending on whether the condition is elective or enabling.

24. Thanks to Gideon Yaffe for emphasizing this point to me.

25. Mark Bittman, Food Matters: A Guide to Conscious Eating with More than 75 Recipes $72(2008)$.

26. Bratman, Intention, Plans, supra note 4, at 34; see also id. at 24-26.

\section{CAMBridge}

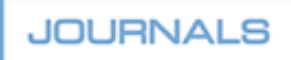

http://journals.cambridge.org 


\section{A. Elements of Bratman's Planning Theory}

Intentions, like other mental states, can be identified as such by their function in a person's reasoning and behavior. Bratman observes that futuredirected intentions are like plans that the agent adopts both to guide her behavior and to coordinate it with others. ${ }^{27}$ Intentions have two characteristic features that allow them to serve those functions. First, and most obviously, A's intention at $\mathrm{t}_{0}$ to $x$ at $\mathrm{t}_{1}$ tends to cause A to $x$ at $\mathrm{t}_{1}$. Second, A's intention at $\mathrm{t}_{0}$ to $x$ at $\mathrm{t}_{1}$ structures A's deliberations and actions between $\mathrm{t}_{0}$ and $\mathrm{t}_{1}$. The first feature is perhaps the more familiar one. Exclusive focus on an intention's causal efficacy with respect to the intended act suggests the billiardball picture that I describe in the introductory paragraphs. Section III describes how it can also give rise to the illusion that there is no intrinsic difference between background and foreground conditions. Less familiar is the role that future-oriented intentions play in structuring an agent's ongoing deliberation and behavior. This section provides a quick overview of Bratman's theory of this function. I argue in Section III that it is here that the difference between background and foreground conditions plays out.

Practical reasoning is a norm-governed activity. To describe the governing norms is to describe both how rational agents should deliberate and how competent agents do deliberate. That is, the relevant norms not only are the rules of practical reasoning but also depict the reasoning habits of competent agents. Having an intention requires having the capacity to adhere to the relevant norms, which means having the right deliberative habits.

Bratman identifies two norms that govern how A's intention to $x$ should influence A's practical deliberation: means-end coherence and consistency. ${ }^{28}$ For the purposes of the analysis here, I ignore a third constraint, agglomerativity, which requires that an agent's intention to $x$ and her intention to $y$ be such that she could also intend $x$ and $y .{ }^{29}$ The consequences of a conditional intention for agglomerativity are similar to those for consistency.

Means-end coherence requires that if A intends to $x$, she also eventually adopt intentions to accomplish the necessary means of xing. Stated otherwise, means-end coherence requires, "roughly, that it not be true that one intends $E$, believes that $E$ requires that one intend means $M$, and yet not intend $M .{ }^{30}$ This constraint goes hand in hand with the fact that intentions are typically but partial plans. Jones's intent to expand into the neighboring storefront does not yet decide how the new space will be designed, who will do the construction work, whether her coffee shop will remain open during construction, and so forth. In order to realize that intention,

27. This theory is laid out in $i d$., passim.

28. See id. at 32-33.

29. See id. at 134-138; Gideon Yaffe, Trying, Intending, and Attempted Crimes, 32 PHIL. ToPICS 505, 512-514 (2004); Ferrero, supra note 10, 95.1.

30. Bratman, Intention, Belief, supra note 4 , at 1 .

\section{CAMBridge}

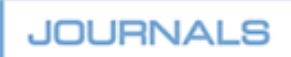

http://journals.cambridge.org 
Jones must eventually intend requisite means of expanding. Means-end coherence therefore "provides rational pressure for the addition of further intentions." 31

The consistency requirement "provides constraints on what further intentions may be introduced," be they intentions to accomplish the means of xing or other projects. ${ }^{32}$ It requires that "one's intentions, taken together with one's beliefs, fit together into a consistent model of one's future." 33 If Jones intends to expand the coffee shop, she cannot consistently also intend to maintain its interior layout unchanged. Whether two intentions are consistent often depends on the agent's other beliefs. Thus if Jones believes that expanding her business will require hiring more employees, her intention to expand is incompatible with an intention to shrink her workforce. If she believes the expanded business will not require more workers, those intentions are compatible.

These two rational constraints-means-end coherence and consistencyground Bratman's claim that intentions do not so much provide an agent with first-order reasons to act as frame her ongoing practical deliberation. Settling on an intention to $x$ provides a second-order reason to exclude from one's deliberation options that are inconsistent with xing and creates second-order reasons to adopt further intentions concerning the means of xing. Intentions therefore "provide special kinds of reasons-framework reasons-whose role is to help determine the relevance and admissibility of options. These reasons do not compete with desire-belief reasons, but rather structure the process of weighing such reasons." 34

The other necessary piece of Bratman's theory is his technical concept of acceptance. Intentions tie into beliefs or belief-like attitudes at several points. First and perhaps most familiarly, a person's practical reasoning is premised on her beliefs. My reasoning from a desire for a snack to an intent to go to the refrigerator passes through my belief that the refrigerator contains food. Second, having an intention to $x$ requires something like a belief that one is able to $x$ and is closely related to the belief that one will $x$. Third, the demands of both means-end coherence and consistency depend on the agent's beliefs. I have already mentioned that "consistency" refers not only to logical consistency (A cannot intend both to $x$ and to not- $x$ ) but to compossible realizability given the agent's beliefs about the world (Jones's intention to reduce her workforce is inconsistent with an intention to expand her business because she believes expansion will require more employees). Means-end coherence is equally belief-dependent. Jones's intention to hire Nathan to do the construction fills in her intention to expand because she believes that expanding requires renovation of the

31. Bratman, Intention, Plans, supra note 4, at 33.

32. Id. at 33 .

33. Bratman, Intention, Belief, supra note 13, at 1 .

34. Bratman, Intention, Plans, and Practical Reason, supra note 4, at 34.

\section{CAMBRIDGE}

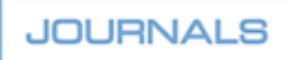

http://journals.cambridge.org 
new space, that she cannot do the work herself, that Nathan can, and so forth.

But belief-type commitments do not function in the same way in our practical and in our theoretical reasoning. ${ }^{35}$ Bratman suggests we reserve the term "belief" for attitudes subject to the requirements of theoretical reasoning and use "acceptance" to denote belief-like attitudes subject only to the requirements of practical reasoning. For the purposes of the argument below, it is enough to observe two differences between belief and acceptance. First, in theoretical reasoning we often assign our beliefs a degree of certainty, though in our practical reasoning we might treat the content of those attitudes as given or simply true. Thus while Jones knows that buildings occasionally catch fire and burn down, in deciding to expand her business into the neighboring storefront she brackets such considerations and assumes the space will be available. There are a number of reasons to accept a proposition in one's practical reasoning that on reflection one would think is subject to some uncertainty. These include simplification, asymmetries in the cost of errors, and the demands of social cooperation. ${ }^{36}$ The net effect is that "practical pressures can make it reasonable of me to accept that $p$ in a certain practical context even if it is not reasonable of me to assign $p$ a probability of 1 in my theoretical reflections." 37

Second, whether one accepts a proposition in one's practical reasoning depends on the context. For the purpose of deciding whether to expand her business, Jones reasonably accepts that she will be able to use the space; when thinking about whether to buy insurance, she allows that accidents happen. The practical pressures for accepting a proposition:

are context-relative in the sense that they apply in only some of the practical contexts in which this proposition is relevant. Such pressures can sometimes make it reasonable for an agent to accept a proposition in a given context, even though she reasonably would not (or, indeed, does not) accept that proposition in a different context in which it is relevant. ${ }^{38}$

Beliefs, in contrast, are not context relative. Theoretical reasoning requires that if I have a belief when reasoning about one matter, I maintain that belief when reasoning about another.

35. See Michael E. Bratman, Practical Reasoning and Acceptance in a Context, in Faces OF Intention: SElection Essays on Intention And Agency, at 15 (1999). Bratman also discusses the basic idea in Bratman, Intention, Plans, supra note 4, at 36-37.

36. Bratman also discusses acceptances tied to special relationships to others, such as loyalty, and the acceptance of propositions that are preconditions of practical reasoning, such as that I have a free will. See Bratman, Practical Reasoning, supra note 35, at 21-26.

37. Id. at 29 .

38. Id. at 20 .

\section{CAMBRIDGe}

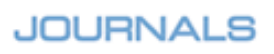

http://journals.cambridge.org 
B. Strictly Conditional, Conditioned, and Biconditional Intentions

I turn now to the structure of conditional intentions. It is a familiar fact that the grammar of natural language does not always mirror the logical structure of the propositions we express in it. This is no less true of reports of conditional intentions. Suppose Jones tells the manager of her coffee shop, "I intend to expand into the space next door if I can get a construction loan." In context, it is reasonable to interpret Jones as saying that she intends to expand if she gets the loan, and that she intends not to expand if she does not. Despite its surface grammar, her statement reports a biconditional intention. She intends that getting a loan shall be a necessary and sufficient condition of expansion. She intends to expand if and only if she gets a loan.

In analyzing A's conditional intention to $x$, it is useful to distinguish A's attitude toward the conditions under which she shall $x$ from her possible attitudes toward xing as such-whether she prefers xing to not-xing, intends to $x$, intends to try to $x$, and so forth. To keep with the example, Jones's intention to expand the coffee shop if and only if she gets a construction loan does not of itself tell us whether she wishes or intends to try to expand. In the context of the above exchange, it seems that she does. But we can imagine other scenarios in which Jones does not want to expand but intends to do so if she gets a construction loan-say, where she has entered into a contract to purchase conditioned on obtaining the loan, and she now wants to be relieved of the obligation.

This section focuses on the different attitudes an agent A might have toward the conditions under which she shall $x$. My claim is that an agent might intend a state of affairs as a sufficient condition on performing an act (A intends to $x$ if $\mathrm{C}$ ), as a necessary condition of performing it (A intends to $x$ only if $\mathrm{C}$ ), or as a necessary and sufficient condition (A intends to $x$ if and only if C). For the moment I leave it open whether these connectives- "if," "only if," and "if and only if"-should be read to accord with the logic of material implication. I argue in Section III that the truth-functional reading at least captures conditional intentions' role in organizing an agent's practical reasoning.

I will call intentions whose content includes sufficient conditions "strictly conditional," intentions that include necessary conditions "conditioned," and intentions that include necessary and sufficient conditions "biconditional." This typology is not defined with reference to the distinctions between foreground and background or between elective and enabling conditions. ${ }^{39}$ The different possible characteristics of a condition, however, interact and limit one another. In this section I describe how elective and then enabling conditions might or might not fall under one or another of these logical types. The relation to background and foreground conditions is a topic of Section III.

39. Ferrero generally assumes that elective conditions are intended as sufficient conditions, while enabling conditions are necessary ones. See Ferrero, supra note 10, \\2.2-2.3.

\section{CAMBridge}

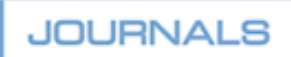

http://journals.cambridge.org 
An elective condition on an intention is not imposed by the world but comes from the agent herself. In some instances an elective condition is a matter of a conscious choice: the agent has decided that the relevant state of affairs shall be a condition of performing the intended act. In others, the condition is adopted without deliberation or reflection, as the result of broader policy-based intentions or simply as a matter of habit. In either case, the condition is not the mere corollary of a belief that one will be able to perform the intended act only if it the condition is satisfied. This is what distinguishes elective from enabling conditions.

An elective condition might be located in the antecedent or the consequent of a conditional intention or in both; that is, elective conditions can appear in strictly conditional, conditioned, or biconditional intentions.

Sometimes the surface grammar of "A intends to $x$ if $\mathrm{C}$ " matches the speaker's meaning, and the sentence reports that $\mathrm{A}$ intends that $\mathrm{C}$ shall be a sufficient but not necessary condition of A's xing. This is commonly the case when $\mathrm{C}$ is a reason to do the intended act. Jones might intend, for example, to expand the coffee shop if but not only if a planned movie theater opens down the street. In that case, she has made a decision that the movie theater opening shall be a sufficient condition of expanding but she has not yet decided what to do if the movie theater does not open-if the condition is not satisfied. We can formally represent the content of such an intention by using the " $\rightarrow$ " connective, stipulating for the moment that it should not be read as a material conditional but as a generic implication operator. Where A intends that $\mathrm{C}$ shall be a sufficient but not necessary condition of A's xing, the structure of her intention is:

$$
\text { A intends }(\mathrm{C} \rightarrow x){ }^{40}
$$

I suggest reserving the term "strictly conditional" for intentions that have the form (2).

A strictly conditional intention need not be combined with any other attitude to effect the act in question. A strictly conditional intention to $x$ if $\mathrm{C}$ suffices to explain the agent's xing when $\mathrm{C}$ pertains. That said, an agent who intends to $x$ if $\mathrm{C}$ might have other attitudes that further illuminate her disposition toward $x$ ing. Thus A might also intend to $x$ if $\mathrm{D}$, whether or not $\mathrm{C}$ pertains. Jones might intend to expand her business if the city council passes a measure to create a business improvement district, whether or not the cinema opens. If the agent has control or influence over whether $\mathrm{C}$ pertains, her attitude toward $\mathrm{C}$ or her other attitudes toward xing can also be highly informative. In the examples, Jones might mean to do everything in her power to ensure satisfaction of the condition-write a letter encouraging the developers to open the cinema, lobby the city council. In other situations,

40. A more rigorous formalization would put a proposition on each side of the operator; that is, (2) should be understood as shorthand for "A intends $(\mathrm{C} \rightarrow \mathrm{A}$ xes)."

\section{CAMBridge}

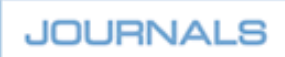

http://journals.cambridge.org 
an agent might prefer not-C or not- $x$, and therefore intend to try to prevent satisfaction of an elective sufficient condition.

Alternatively, an agent A might intend that $\mathrm{C}$ be a necessary but not sufficient condition of her $x$ ing; that is, she might intend to $x$ only if elective condition $\mathrm{C}$ is satisfied without yet deciding whether she shall $x$ if $\mathrm{C}$. Thus Jones might decide that she will perform her promise to purchase only if her architect determines the space is suitable, though even then she might choose not to buy it. Here the structure of Jones's intention is:

$$
\text { A intends }(x \rightarrow C)
$$

I will use the term "conditioned" for intentions of form (3). The clearest natural-language description of an elective conditioned intention is often its contrapositive: A intends not to $x$ if not-C (Jones intends not to purchase if the architect does not report the space is suitable). Elective conditioned intentions commonly appear in policy-based intentions, such as an intention never to swim on a full stomach or never to drive drunk, which have the forms: A intends (swim $\rightarrow$ A has an empty stomach) and A intends (drive $\rightarrow \mathrm{A}$ is sober $).{ }^{41}$

If we read conditional intentions as operating according to the logic of material implication-and I argue in Section III that we should with respect to their consequences for the agent's deliberations-the equivalence of the contrapositive means that every strictly conditional intention is equivalent to a conditioned intention, and vice versa. A's intention $(\mathrm{C} \rightarrow x)$ is functionally equivalent to her intention (not- $x \rightarrow$ not-C), and A's intention $(x$ $\rightarrow \mathrm{C}$ ) is functionally equivalent to her intention (not- $\mathrm{C} \rightarrow$ not- $x$ ). I believe this is correct. A formal analysis of the rational constraints that an agent's intentions impose on her deliberations could do without one or the other category. Separating them out, however, will be useful in analyzing the different ways in which conditions figure into practical reasoning. And the opacity of propositional attitudes means that an agent who reports a conditioned intention might not admit to the corresponding strictly conditional intention, or vice versa.

Unlike strictly conditional intentions, a conditioned intention as such does not tell us the agent's attitude toward the act should the condition be satisfied. A's intention $(x \rightarrow \mathrm{C})$ does not say what A plans to do if $\mathrm{C}$ pertains. ${ }^{42}$ This is most obviously the case in policy-based intentions. My intention to swim only on an empty stomach, together with the fact that it

41. Policy-based intentions can also be strictly conditional or biconditional.

42. Luca Ferrero suggests in correspondence that this might mean that "conditioned intentions" are not really intentions as the agent has not yet decided what to do in scenarios in which the condition is satisfied but only in scenarios in which the condition is not satisfied. This would explain why the contrapositive is the more natural expression. According to this objection, only strictly conditioned intentions are true intentions, while what I call "conditioned intentions" are mere constraints on an agent's future deliberations. This objection is of a piece with Ferrero's rejection of the truth-functional reading of conditional intentions. Ferrero

\section{CAMBRIDGE}

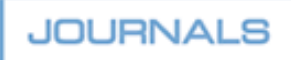

http://journals.cambridge.org 
has been two hours since I last ate, does not determine whether I intend to swim. But the point also applies to one-shot conditioned intentions. Jones intends that a favorable architect's report shall be only a necessary, not a sufficient, condition of purchasing. Consequently, as distinguished from strictly conditional intentions, A's conditioned intention to $x$ only if $\mathrm{C}$ and C's pertaining are never a sufficient explanation of A's subsequently xing. For that we must refer to A's other attitudes, like her intention to $x$ or her intention to try to $x$.

Often more salient than either strictly conditional or conditioned intentions are elective biconditional intentions. A biconditional intention has the structure:

$$
\text { A intends }(x \leftrightarrow C) \text {. }
$$

So interpreted, Jones's statement, "I intend to expand the coffee shop if I can get a loan," reports that Jones intends to expand if she obtains a loan and not to expand if she does not. That is, Jones intends that getting a loan shall be a necessary and sufficient condition of expanding. A's elective biconditional intention to $x$ if and only if $\mathrm{C}$ is sufficient to explain the fact that $\mathrm{A} x \mathrm{xes}$ when C pertains. Like other conditional intentions, however, an agent's other attitudes toward xing might further illuminate the biconditional intention's place in her practical reasoning.

Enabling conditions exhibit less variety in their logical structure. An enabling condition is a condition of the possibility of performing the intended act. By definition, then, enabling conditions are always necessary conditions. It does not follow, however, that they can appear in conditioned intentions. A conditioned intention has form (3) above: A intends $(x \rightarrow \mathrm{C})$. Substituting an enabling condition for $\mathrm{C}$ in (3) produces an ill-formed proposition. What a person intends is within her control and is often a matter of decision. We do not have the ability to control or decide the conditions of the possibility of our acts. Recall Jones's intent to purchase the building only if it is not condemned. Jones does not intend to purchase only if there is no condemnation; the world forces that condition on her. Rather than substituting in

would allow that A might intend (not-C $\rightarrow$ not- $x$ ) but rationally not intend the contrapositive, $(x \rightarrow \mathrm{C})$.

I am not convinced that a conditioned intention expressed as such is not an intention, although of course I grant that it does not specify what the agent shall do if the condition is satisfied. The question is in part a semantic one: How should we use the word "intention"? Conditioned intentions are plans that constrain one's future deliberations and actions. I argue in Section III that they do so in ways that parallel strictly conditional and biconditional intentions. And because I advocate a truth-functional reading of conditional intentions, I am willing to grant that a conditioned intention is equivalent for the purposes of the agent's deliberations to the strictly conditional contrapositive-which would make it odd to say that it is not an intention. All of this recommends, to my mind, a use of "intention" that is more inclusive.

\section{CAMBridge}

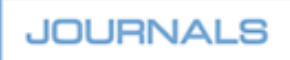

http://journals.cambridge.org 
(3), we should therefore say:

$$
\text { A believes or accepts }(x \rightarrow \mathrm{C}) \text {. }
$$

A cannot intend that enabling condition $\mathrm{C}$ is a necessary condition of her xing, though she can believe or accept that it is.

If an agent has an intention with respect to xing, it will in all likelihood include an intention to $x$ if she can. This might be because A intends to $x$ or intends to try to $x^{43}$ Thus, absent other conditions or considerations, Jones's intention to try to buy the building, together with her belief that she can do so only if it is not condemned, entails an intent to purchase if it is not condemned. That is, Jones has an attitude of the form:

$$
\text { A believes }(x \rightarrow \mathrm{C}) \text { and } \mathrm{A} \text { intends }(\mathrm{C} \rightarrow x) \text {. }
$$

In other contexts, an agent might have an attitude of form (6) for reasons other than an intent to $x$ or to try to $x$. I might intend to attend a faculty meeting if it occurs but hope that it does not happen and even encourage the dean to cancel it. I am not trying to attend the faculty meeting, though I have an intention of form (6). In the analysis that follows, I assume that (6) describes the minimal content of an intention that involves an enabling condition. While not equivalent to a biconditional intention, it is close enough for my purposes. I therefore treat (4), A intends $(x \leftrightarrow C)$, as shorthand for (6) as well.

The fact that enabling conditions appear only in something like biconditional intentions marks a significant difference between enabling and elective conditions. An elective condition might be intended as a sufficient, as a necessary, or as a necessary and sufficient condition of acting; that is, an intention subject to an elective condition might be strictly conditional, conditioned, or biconditional. In contrast, enabling conditions, insofar as they figure into the content of an agent's attitudes, are always believed to be necessary and can therefore be intended only as sufficient conditions of acting. Intentions that include enabling conditions in their scope are always biconditional in the sense described above.

\section{A PLANNING THEORY OF FOREGROUND AND BACKGROUND CONDITIONS}

The planning theory holds that future-directed intentions have two characteristic features. An intention to $x$ is the sort of thing that tends, first, to

43. If $\mathrm{A}$ accepts the satisfaction of $\mathrm{C}$ in the sense described in the next section, then she might simply intend to $x$. If she does not accept the satisfaction of $\mathrm{C}$, then she might rationally be able only to try to $x$. For complications in the distinction between intending and trying, see Bratman, Intention, Plans, supra note 4, at 113-22; Carl Ginet, Trying to Act, in Freedom And Determinism 89 (J.K. Campbell et al. ed., 2004); Yaffe, Trying, supra note 29.

\section{CAMBridge}

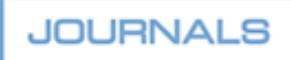

http://journals.cambridge.org 
cause the agent to $x$ and, second, to influence in the mean time the agent's practical deliberations and other actions in accordance with the norms of consistency and means-end coherence.

Attending only to the first characteristic can make it appear as if the distinction between background and foreground conditions has more to do with what is known about the agent's practical attitudes than the attitudes themselves. Let $P_{i}$ represent the probability of Jones realizing an unconditional intention to perform under the hypothetical contract to purchase, $\alpha_{\mathrm{F}}$ the probability that she will obtain a construction loan, and $\alpha_{\mathrm{B}}$ the probability that a Starbucks will not open. Jones's foreground-conditional intention to perform if and only if she gets a loan entails that the probability of her performing is $\alpha_{\mathrm{F}}\left(\mathrm{P}_{\mathrm{i}}\right)$. A background condition that Starbucks not move into the neighborhood entails that the probability is $\alpha_{\mathrm{B}}\left(\mathrm{P}_{\mathrm{i}}\right)$. With respect to performance of the intended act, background and foreground conditions appear to have the same sorts of consequences.

Seeing this, one might conclude that the difference between background and foreground conditions lies not in underlying attitudes but in what the agent or her interlocutor knows about them. Hence the awareness theory, according to which foreground conditions are just those conditions the agent realizes or attends to. Alternatively, one might look to the conversational logic of first-person reports. ${ }^{44}$ On this approach, which is implicit in Ayres and my earlier work, background conditions are those conditions within the range of the speaker and hearer's mutual expectations, while foreground conditions are those about which the speaker reporting her intention knows more than the hearer. ${ }^{45}$

Suppose Jones tells her manager that she intends simpliciter to expand the business in six months. Both know that a Starbucks opening across the street is the sort of event that might cause Jones to cancel those plans. So long as Jones does not think a Starbucks is particularly likely, she has no reason to communicate that condition. But if she has heard that Starbucks has been scouting locations nearby, she might mention the condition to inform the manager indirectly of that fact. Similarly, if the manager has no reason to know that Jones will need a loan to make the necessary improvements, Jones would then have a reason to tell him of that condition on her intent to expand. On this theory of conversational pragmatics, background conditions on an expressed intention are those that correspond to the speaker and hearer's mutual background understanding, while foreground conditions are conditions about which the speaker knows more than the hearer.

While there is something to the pragmatic theory as a description of the norms governing expressions of intent, it is not a satisfactory account of the difference between background- and foreground-conditional intentions.

44. The theory I describe in this and the next paragraphs builds on David Pears's analysis of implicature for expressions of intent in Pears, Intention and Belief, in EsSAYS ON DAVIDSON: ACTIONS AND Events 75, 84-88 (Bruce Vermazen \& Merrill B. Hintikka eds., 1985).

45. See Ayres \& Klass, supra note 3, at 26-29.

\section{CAMBridge}

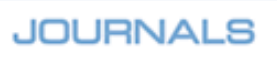

http://journals.cambridge.org 
Attention to the other function of future-directed intentions-structuring an agent's practical deliberations in accord with consistency and means-end coherence-suggests that the distinction refers to a difference in kind. This section argues that this is the difference between an agent who accepts the satisfaction or nonsatisfaction of the condition and an agent who accepts neither. Background conditions on an agent's intention are those conditions she accepts in her practical deliberations as satisfied or nonsatisfied, while foreground conditions are those whose satisfaction the agent treats as an open question. This is similar to an approach advocated by Luca Ferrero. ${ }^{46}$ Drawing the line at acceptance of the condition accounts for the different ways background- and foreground-conditional intentions shape an agent's practical reasoning.

The analysis below uses the formal notation developed in Section II to distinguish between strictly conditional, conditioned, and biconditional intentions. To mark whether a condition is background or foreground, I attach the subscripts "F" and "B" to the connectives. For example, "A intends $(\mathrm{C}$ $\rightarrow_{\mathrm{F}} x$ )" should be read to say that A has a foreground strictly conditional intention to $x$ if $\mathrm{C}$, while " $\mathrm{A}$ intends $\left(\mathrm{C} \leftrightarrow_{\mathrm{B}} x\right)$ " says that $\mathrm{A}$ has a background biconditional intention to $x$ if and only if $\mathrm{C}$.

My thesis is that a background condition is one that the agent accepts as satisfied or as not satisfied. The analysis below focuses on the practical consequences of accepting the condition as satisfied. Because I advocate a truth-functional reading of the deliberative consequences of conditional intentions, which permits substitution of the contrapositive, the argument can easily be extended to cover acceptance of the condition's nonsatisfaction. ${ }^{47}$ I consider the implications of acceptance of the condition for consistency and for means-end coherence in turn.

46. See Ferrero, supra note 10 , $₫$ ฯ 4.2-4.3, 6.3, 7.2, 8.2.

47. As an example, suppose $\mathrm{A}$ intends $(x \rightarrow \mathrm{C})$ and that $\mathrm{A}$ accepts that $\mathrm{C}$ is not satisfied. On the proposed theory, her conditioned intention $(x \rightarrow \mathrm{C})$ is therefore background-conditional. Because $\mathrm{A}$ accepts that $\mathrm{C}$ is not the case, in that practical context she should also accept that not-C is the case; that is, she should accept satisfaction of the condition of her functionally equivalent strictly conditional intention (not-C $\rightarrow$ not- $x$ ), which is therefore also backgroundconditional. It is not difficult to show that the rational constraints imposed by A's intention $(x \rightarrow \mathrm{C})$ where $\mathrm{A}$ accepts the nonsatisfaction of $\mathrm{C}$ are the same as the rational constraints imposed by an intention (not-C $\rightarrow$ not- $x$ ) where A accepts the satisfaction of not-C. Similar arguments can be constructed for strictly conditional and biconditional intentions.

This is not a merely technical point; it corresponds to how we describe intentions. Suppose Jones has a policy-based intention of donating found money to charity. If she reflects on the matter, she might decide that if she ever wins the lottery, she will give the money away. Because she never buys lottery tickets, she accepts that the condition of winning the lottery will not be satisfied. But her attitude is not inert. Though it creates no rational pressure to intend the means of donating any winnings (such as choosing a charity), it imposes consistency constraints on Jones's practical reasoning. The attitude entails, for example, that it would be irrational for Jones to plan on funding renovations to her coffee shop by playing the lottery (and not only because of the low probability of winning). Jones's intention to give any lottery winnings to charity is background-conditional because she accepts the nonsatisfaction of the condition.

Thanks to Luca Ferrero for pointing out the complications raised by the contrapositive on my approach.

\section{CAmbridge}

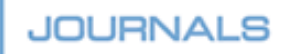

http://journals.cambridge.org 


\section{A. Consistency}

I begin with an obvious case: a foreground biconditional intention, such as Jones's intention to purchase if and only if she obtains a construction loan. On the proposed theory, characterizing the condition as foreground says that Jones accepts neither that she will get a loan nor that she will not get one. This is intuitively plausible. There are two reasons for Jones to mention the condition in conversation or attend to it in her practical reasoning: her belief that she might not get a loan and her decision that if she does not, she will not perform her promise to purchase. That is, Jones is planning for two possible futures, or two scenarios: ${ }^{48}$ one in which she obtains a loan and one in which she does not. She intends in the first to perform and in the second not to do so.

The fact that an agent treats the condition in her biconditional intention as an open question has obvious implications for the consistency of her practical attitudes. ${ }^{49}$ For example, while Jones's simple intention to expand the coffee shop would exclude a plan to keep the interior unchanged, her foreground biconditional intention does not. She expects that if she does not obtain a loan, she will not expand, in which case she might keep the coffee shop as it is. Her foreground biconditional intention to expand (if and only if she gets a loan) permits her to intend conditionally to keep the layout the same (only if she does not obtain a loan).

This suggests a truth-functional reading of the consistency consequences of foreground biconditional intentions. A's behavior complies with her intent $\left(x \leftrightarrow_{\mathrm{F}} \mathrm{C}\right)$ in two possible states of affairs: $\mathrm{C}$ pertains and $\mathrm{A} x \mathrm{es}$, and $\mathrm{C}$ does not pertain and A does not $x$. Thus while A's unconditional intention to $x$ excludes from A's deliberation plans that entail A not-xing, A's foreground biconditional intention to $x$ if and only if $\mathrm{C}$ excludes from her deliberations only plans that entail (a) A xing and not-C, and (b) A not-xing and C. This analysis does not depend on whether the condition is elective or enabling. An intention to purchase the building if and only if the city does not condemn it is of the same structure and has similar consequences for the consistency of Jones's deliberations. (It will be recalled that in these cases, one direction of the biconditional is not an intention but a belief or acceptance regarding the conditions of the possibility of acting.)

The truth-functional reading also captures the consistency constraints of strictly conditional and conditioned intentions. Jones's foreground strictly conditional intention to expand the coffee shop if (but not only if) the movie theater opens excludes from her deliberations plans in which the theater opens and she does not expand but leaves open for her deliberative consideration states of affairs in which (a) it opens and she expands, (b) it does not open and she does not expand, and (c) it does not open and she nonetheless expands. Similarly, Jones's foreground conditioned intention

48. See Yaffe, Conditional Intent, supra note 8, at 292-293.

49. See id. at 294-295; Ferrero, supra note 10, 95.1 n.37.

\section{CAMBridge}

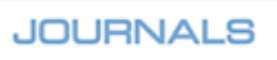

http://journals.cambridge.org 
to expand only if (but perhaps not if) her architect confirms the building's suitability excludes from her deliberations only plans that entail expanding against the architect's advice. It permits the consideration of possible futures in which (a) the architect reports that the space is suitable and she expands, (b) he reports that it is suitable and she does not expand, or (c) he reports that it is unsuitable and she does not expand.

My claim here is that a truth-functional reading of the content of foreground-conditional intentions captures the consistency demands they impose. There is an argument that this is too permissive-that this reading does not describe all the ways that conditional intentions constrain an agent's deliberations. The argument turns on situations in which satisfaction of the condition is within the agent's control. ${ }^{50}$ Consider a biconditional intention of the form: A intends $\left(\mathrm{C} \leftrightarrow_{\mathrm{F}} x\right)$. On the truth-functional reading of the biconditional, not- $\mathrm{C}$ and not- $x$ together establish the truth of " $\left(\mathrm{C} \leftrightarrow_{\mathrm{F}} x\right)$." If $\mathrm{C}$ is within A's control, the truth-functional analysis suggests that A can realize her biconditional intention by preventing the satisfaction of $\mathrm{C}$ and then not xing. And this can seem wrong. Suppose Jones intends to purchase if and only if she obtains a construction loan. It seems odd to say that she might realize such an intention by not applying for a loan and then not purchasing. Yet that is what the truth-functional reading entails. Similar intuitions apply to strictly conditional and conditioned intentions. $^{51}$

50. See Hector Neri Castañeda, Some Reflections on Wilfrid Sellars' Theory of Intention, in Action, Knowledge and Reality: Critical Studies in Honor of Wilfrid Sellars 27, 34-35 (H.N. Castañeda ed., 1975).

Ferrero advances a different argument against a truth-functional reading: that it does not capture what it means to carry out an intention.

The only way in which a conditional intention [to $\varphi \mathrm{IF} \mathrm{C}$ ] can be genuinely carried out is by $\varphi$-ing in those circumstances when $\mathrm{C}$ obtains by the time of the intended action. There is nothing that counts as carrying out a conditional intention when, by the time of action, $\mathrm{C}$ can no longer obtain.... The alleged discharging of a conditional intention when $\mathrm{C}$ can no longer obtain would not amount to a practical achievement.

Ferrero, supra note 10, \2.8; see generally id. $₫$ \2.5-3.2.

My claim here concerns only the deliberative constraints that conditional intentions impose. The argument is not designed to show that a truth-functional reading captures every aspect of conditional intentions - though it would be an important piece of such a showing. Still, I am not persuaded by Ferrero's argument, which I think proves too much. Suppose that I unconditionally intend to stop smoking and that shortly after I adopt the intention, the government bans the sale of tobacco products. I can no longer smoke. In this case, as in Ferrero's example, the world has conspired to realize the object of my intention without any effort by me. This does not mean that I did not intend to stop smoking. It rather reflects the fact that carrying out an intention, whether conditional or not, requires more than moving into a state of the world in which the propositional object is true.

51. Thus it might seem strange to say that Jones might realize an intention to expand if the theater opens (a strictly conditional intention) by taking actions to prevent it from opening, or odd to say that Jones could realize her intention to expand only if her architect approves of the space (a conditioned intention) by going out of her way to convince the architect that it does not suit her needs.

\section{CAMBridge}

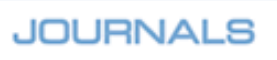

http://journals.cambridge.org 
These intuitions, however, are context-dependent. Consider the intentions involved in contingency planning. Suppose I fully intend to write a paper for an upcoming conference. Because I recognize that I might not finish it in time, I adopt an intention that if the new paper is not yet finished (an elective condition), I will present an older one. My strictly conditional intention is: Klass intends (I have not finished new paper $\rightarrow_{\text {F }}$ present old paper). In this situation I might do my best to falsify the antecedent without lapsing into irrationality. One can construct similar examples involving enabling conditions. Thus imagine a loving niece who means to do everything in her power to keep her rich uncle alive yet plans that should she inherit from him, she will take the trip to Paris she has always dreamed of. Her biconditional intention with respect to Paris is: Niece intends (uncle dies $\leftrightarrow_{\text {F }}$ go to Paris). Yet here too we would allow that she might rationally intend to prevent satisfaction of the condition.

My suggestion is that our intuitions in all of these cases are driven not by the conditional intention per se but by the agent's reasons for adopting it, by her other intentions, and by the broader plans or policies in which the conditional intention fits. Consider again Jones's intention to purchase if and only if she obtains a construction loan. If she wants to expand, she might adopt the biconditional intention because she wants to purchase the neighboring storefront and judges that it will not be worth anything to her if she cannot pay to renovate it. But suppose the sales contract contains a contingency clause providing that if Jones cannot get a loan she is not required to purchase, and she wants to get out of the deal because a Starbucks is opening across the street. In these circumstances, Jones might reason that the only way to get out of the contract without incurring liability for breach is to do her best not to obtain a loan. ${ }^{52}$ Jones's intent to purchase is still biconditional, but now she is attempting to defeat the condition.

I am arguing here for a thin conception of intentions, according to which intentions are individuated by the consistency, means-end-coherence, and other rational demands they impose on an agent's deliberations, but not by the agent's reasons for adopting them or the broader plans or projects in which they figure. ${ }^{53}$ On this thin conception, Jones's foregroundconditional intention to purchase if and only if she obtains a loan is the same whether she adopts it because she intends to try to expand and believes she

52. Jones is ignorant of the contractual duty of good faith.

53. This claim is similar to Wilfrid Sellars's comments on the difference between the "logic, strictu sensu, of intentions" and the conceptual truth that some states of affairs "belong in their content by virtue of being believed to be the case or about to be the case," while others "are considered by the agent to be "up to me.'" Wilfrid Sellars, Conditional Promises and Conditional Intentions (Including a Reply to Castañeda), in AgENT, LANGUAGE, AND THE STRUCTURE OF THE WORLD 195, 213 (J. Tomberlin ed., 1983). Sellars argues that the latter differences result from the particular reasoning that produces the intention. Id. at 217-219. It is also worth keeping in mind Sellars's suggestion that our intuitions in these cases sometimes concern "not the logic of intentions as such, but the logic (in a suitably broad sense) of conditional commitments," which one can undertake with an expression of intent. Id. at 206.

\section{CAMbridge}

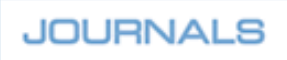

http://journals.cambridge.org 
needs the loan to do so or because she wants to get out of the sales contract and thinks being denied a loan is her best exit strategy. While the different reasons for adopting the biconditional intention impose different constraints on Jones's deliberations, those constraints are not part of the intention itself. ${ }^{54}$

This is not to say that a thicker conception of intentions, according to which Jones's two conditional intentions are not functionally equivalent, is impossible or incoherent. But to individuate intentions with reference to the agent's reasons for holding them would be to rob the concept of much of its analytic value. By distinguishing intentions from those reasons, we identify an attitude that plays a distinctive role in our practical reasoning. Such intentions constrain an agent's deliberation and influence her action in a way that is rational, without requiring reasons to enter into her decisions every step along the way. ${ }^{55}$ And even if we chose the thicker conception and decided to individuate intentions in light of agent's reasons for adopting them, we would still want a way of identifying what is common between attitudes that the thinner conception treats as the same; that is, we would still want something like the thin conception of intentions with its truthfunctional reading of a foreground condition's consistency consequences. Finally, as becomes clear in Section IV, the legal importance of a promisor's foreground-conditional intent to perform turns in part on cases in which the promisor intends to realize that intention by preventing satisfaction of the condition, as permitted by the truth-functional reading.

The last several paragraphs have taken us fairly deep into the analytic weeds. While the details differ when satisfaction of the condition is under an agent's control, on both the thin and thick conceptions, foreground conditions on an agent's intention have the same sorts of consistency consequences: they relax the consistency demands the intention would otherwise impose, permitting the agent to consider plans that under certain circumstances entail not performing the act in question. With respect to consistency, this is the core difference between a foreground-conditional and an unconditional intention.

What of the consistency implications of background conditions? On the proposed theory, an intention is background-conditional if it is conditional and the agent accepts the condition's satisfaction or its nonsatisfaction. Acceptance differs from belief in that consistency does not require an agent who accepts $S$ in one context to accept $S$ in others. In considering whether to purchase the building next door, it is rational for Jones to accept that it will serve her purposes; in deciding whether to buy fire insurance, it is rational for her to recognize that accidents happen. That said, consistency would seem to require at least that an agent who accepts $\mathrm{S}$ in one context

54. This thesis marks another point where my approach differs from Ferrero's. Ferrero would analyze the content of a contingency plan, for example, as including the fact that it is subordinated to a different, primary pursuit. Ferrero, supra note 10, 96.6 n. 60 .

55. See, e.g., Bratman, Intention, Plans, supra note 4, at 28-35, 64-70, 87-91.

\section{Cambridge}

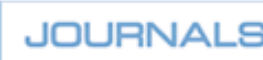

http://journals.cambridge.org 
not accept not-S in others. It would be irrational for Jones to accept, when deciding whether to buy, that she will be able to expand into the building, and then decide to insure it because she expects it to burn down. It is one thing to recognize, on reflection or in other practical deliberations, that one's practical assumptions might be wrong; it is another to believe or accept in other contexts that they are wrong. The former is rational; the latter, irrational. ${ }^{56}$

If this is right, background conditions do not relax consistency constraints in the same way that foreground conditions do. Suppose A has a (strictly conditional) intention to $x$ if $\mathrm{C}-\mathrm{A}$ intends $\left(\mathrm{C} \rightarrow \rightarrow_{\mathrm{B}} x\right)$ - or a (biconditional) intention to $x$ if and only if $\mathrm{C}-\mathrm{A}$ intends $\left(\mathrm{C} \leftrightarrow_{\mathrm{B}} x\right)$. In either case, A's acceptance of $\mathrm{C}$ excludes from her deliberation any course of action that entails not-xing. Any state of affairs in which A does not $x$ will entail not-C, which ex hypothesi is incompatible with A's acceptance of C. In contrast to similar foreground conditions, the consistency constraints imposed by a background strictly conditional or background biconditional intention to $x$ are no less stringent than those imposed by an unconditional intention to $x$. Acceptance of the condition has different implications for conditioned intentions. A conditioned intention as such does not yet tell us the agent's attitude with respect to the act upon satisfaction of the condition. If $\mathrm{A}$ intends to $x$ only if $\mathrm{C}-\mathrm{A}$ intends $\left(x \rightarrow{ }_{\mathrm{B}} \mathrm{C}\right)$ - her acceptance of $\mathrm{C}$ renders that intention compatible with both xing and not-xing. A background conditioned intention by itself imposes no consistency constraints on the agent's further deliberations with respect to the act in question.

This is not to say that background conditions play no role in consistency evaluations. As Ferrero observes, A's background belief that C is a necessary enabling condition of her $x$ ing - in my notation, her belief $\left(x \rightarrow{ }_{B} \mathrm{C}\right)$ - partly determines which other intentions are consistent with her intention to $x$. Suppose Jones believes that she will have the money to purchase the building next door only if the coffee shop remains in business. If Jones accepts that the coffee shop will stay in business and intends to make the purchase, the background condition renders her intent to do so incompatible with a new plan to close the coffee shop. "[T] o determine whether two intentions can be agglomerated, we have to see whether there is any incompatibility in their preconditions. If there is an incompatibility, the pursuit of one plan sooner or later is going to make the pursuit of the other impossible." 57

Ferrero makes this point for enabling conditions, but it applies equally to elective ones. Thus suppose Jones could pay for the purchase out of her own pocket but has a policy of never using personal funds to pay for business expenses. This policy, together with the above belief, entails an electively conditional intention to buy the building only if the coffee

56. Compare Bratman's comments on the inconsistency of intending $x$ and believing that one will not $x$. Id. at 37-41.

57. Ferrero, supra note $10,96.5$. Ferrero puts this point in terms of the agglomerativity constraint, but it holds for consistency as well.

\section{CAMbridge}

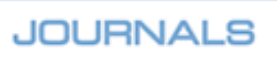

http://journals.cambridge.org 
shop remains open. Adherence to that intention would again render selling the coffee shop incompatible with Jones's intent to purchase. The consistency implications of the condition depend not on whether it is enabling or elective but on whether the agent is practically committed to its being a necessary condition of performing the act in question. That practical commitment might be the result of a belief, an acceptance, or an intention.

These observations are of a piece with the fact that the consistency constraint requires not only logical consistency but consistency with the agent's practical commitments as a whole, including her other intentions, beliefs, and acceptances. The consistency of A's intention to $x$ with her other possible intentions depends on A's commitments as to what xing entails. These include both the conditions of the possibility of her xing (the enabling conditions Ferrero emphasizes) and the conditions under which she intends to $x$ (elective conditions), not to mention the natural consequences of $x$ ing, whether intended or not. ${ }^{58}$

So far I have discussed only background necessary conditions, in which A believes or intends that she shall $x$ only if $\mathrm{C}$ and accepts $\mathrm{C}$. The results carry over a fortiori to background necessary and sufficient conditions, where $\mathrm{A}$ intends to $x$ if and only if $\mathrm{C}$ and accepts that $\mathrm{C}$. Here, too, the condition figures into the consistency demands of A's intention: a commitment to xing precludes courses of action that entail not-C. The consistency implications of background sufficient conditions are subtler. If A accepts $\mathrm{C}$, her intention to $x$ if $\mathrm{C}$ would seem to impose the same consistency constraints as an unconditional intention to $x$ would. The background strictly conditional intention does, however, constrain A's reconsideration of xing: she may consistently decide to not- $x$ only if she no longer accepts $\mathrm{C}$ or gives up her strictly conditional intention to $x$ if $\mathrm{C}$.

With respect to the consistency of an agent's deliberations, then, background and foreground conditions have something like the opposite effects. A foreground condition relaxes the consistency constraints the intention would otherwise impose, allowing the agent to plan for some (but not

58. This last point argues that Jones's background conditioned intention to expand only if the coffee shop is still in business imposes consistency constraints of the same sort as her belief that if she expands she will need to hire more employees. While one refers to a precondition of expanding and the other a necessary side effect of doing so, both are entailments of performing the intended act and so figure into what is consistent with so acting.

This explains how known side effects enter into the content of future-directed intention without, in an important sense, being intended. A's intention to $x$ with side effect S screens out an intention to $y$, where a condition of the possibility of ying is not-S. While this is beyond the scope of this article, I believe this point requires refining Bratman's claim that while choice is holistic-encompassing the entire scenario intended-future-directed intentions are not. See Bratman, Intention, Plans, supra note 4, at 153-155. Bratman is right to observe that known side effects do not impose a pressure to intend the means of their realization. But they do figure into the consistency constraints that the intention imposes. Future-directed intentions are also holistic, though not every element in the intentional object plays the same role.

\section{CAmbridge}

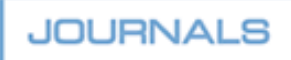

http://journals.cambridge.org 
all) states of affairs in which she does not perform the act in question. Background conditions, on the contrary, figure into the articulation of consistency constraints, further limiting what other intentions the agent may consider. While foreground conditions permit the agent to entertain a wider range of possible plans, background conditions restrict the plans she may contemplate.

\section{B. Means-End Coherence}

I turn now to the consequences of background and foreground conditions for means-end coherence. My thesis is that a foreground necessary or necessary and sufficient condition on an intention reduces the rational pressure to intend requisite means of performing the act, that a foreground sufficient condition has no immediate implications for means-end coherence, and that background conditions generally impose no special pressure to intend requisite means of acting.

Ferrero begins to get at the different means-end consequences of background and foreground conditions when he observes that preparing for not-C might be more or less reasonable depending in part "on the agent's expectation about the obtaining of C":

In certain contexts, the most reasonable conduct is to accept that $\mathrm{C}$ and behave as if the intention were circumstantially unconditional. At the opposite extreme, C might be so remote a possibility and $\varphi$-ing so unimportant that the most reasonable strategy is to do only what is minimally required to keep the possibility of her $\varphi$-ing alive in case C obtains, while devoting all her other available resources to planning and preparing for $\mathrm{C} .{ }^{59}$

Ferrero's first case, in which the agent accepts that $\mathrm{C}$ will be satisfied, describes a background-conditional intention. Here Ferrero's observation seems basically correct, though it skips over some details. If A intends C to be a sufficient or a necessary and sufficient condition of her xing and $A$ accepts $\mathrm{C}$-in my notation, if $\mathrm{A}$ intends $\left(\mathrm{C} \rightarrow \rightarrow_{B} x\right)$ or $\mathrm{A}$ intends $\left(x \leftrightarrow_{B} \mathrm{C}\right)$-then means-end coherence requires of $\mathrm{A}$ exactly what it would if $\mathrm{A}$ intended to $x$ simpliciter. A should invest no more or less thought and energy in realizing the means of $x$ ing than if she had an unconditional intent to $x$. If Jones intends to expand her business if (or if and only if) the movie theater opens and then learns that it will open, means-end coherence requires her to take precisely those steps it would require if she unconditionally intended to expand.

Accepting the satisfaction of a necessary but not sufficient condition has somewhat different means-end consequences. If $\mathrm{A}$ intends or believes that she shall $x$ only if $\mathrm{C}$-if A intends or believes $(x \rightarrow \mathrm{C})$ - then her acceptance

59. Ferrero, supra note $10,95.2$.

\section{CAMBRIDGE}

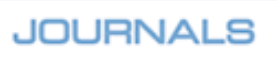

http://journals.cambridge.org 
of $\mathrm{C}$ renders that attitude inert with respect to the requirements of meansend coherence. If I have a policy-based intention to swim only on an empty stomach, my belief or acceptance that I have not eaten in the past two hours does not yet say whether I intend to swim. If Jones intends to purchase the building only if, but not necessarily if, her architect reports that the space is suitable, and the architect's report is positive, Jones's subsequent actions will accord with her conditioned intention whether she purchases or not. ${ }^{60}$

Ferrero's second case, in which the agent treats satisfaction of $\mathrm{C}$ as an open question, describes a foreground-conditional intention. Here things are a bit more complex.

First, notice that Ferrero's observations have more force when applied to conditioned or biconditional intentions. If A has a foreground strictly conditional intention that $\mathrm{C}$ shall be a merely sufficient condition of her xing-A intends $\left(\mathrm{C} \rightarrow_{\mathrm{F}} x\right)$-her practical belief that $\mathrm{C}$ is unlikely to be satisfied might have few consequences for her assessment of whether she will $x$. Should it turn out that not-C, her strictly conditional intention permits her to choose to $x$ anyway. Thus if Jones intends to expand if but not only if the movie theater opens and then finds out that it is unlikely to open, she might still want to plan in a way that makes it possible to expand, as she has not yet decided whether to do so in those circumstances. If, on the contrary, A's intention is conditioned or biconditional-A intends $\left(x \rightarrow_{\mathrm{F}}\right.$ C) or $\left(x \leftrightarrow_{F} \mathrm{C}\right)$-not-C requires that she not $x$. If Jones intends to expand if and only if she obtains a construction loan, learning that she is unlikely to be approved for a loan means that she should plan on not expanding. The fact that an intention is foreground conditioned or biconditional has more immediate consequences for means-end coherence than does the fact that it is foreground strictly conditional.

Second, so long as A treats the satisfaction of $\mathrm{C}$ as an open question, her foreground-conditional intention will put her under some rational pressure to intend necessary means of xing. A person's attitude toward a proposition that exerts no rational pressure on her to realize it in possible future states of the world might qualify as a wish or a desire but is not an intention.

Third, it does not follow that a foreground-conditional intention to $x$ exerts the same degree of rational pressure as an unconditional intention to $x$ would. If A intends $\left(x \rightarrow_{\mathrm{F}} \mathrm{C}\right)$ or if she intends $\left(x \leftrightarrow_{\mathrm{F}} \mathrm{C}\right)$ and if she considers it possible that not-C, her investment in preparing to $x$ might well be tied to her estimation of the probability of $\mathrm{C} .{ }^{61}$ The less likely she considers $\mathrm{C}$, the less rationality is likely to require or even permit

60. The same holds for Jones's belief that no condemnation of the property is a necessary condition of purchasing if she then discovers that it will not be condemned. It makes no difference whether the necessary condition is elective or enabling.

61. But not in all cases. If, for example, A has a reason to intend or attempt to $x$ other than the desirability of xing, such as in toxin-puzzle-type cases, a foreground enabling condition might not affect how much it is rational for A to invest in the means of xing.

\section{CAMBRIDGE}

http://journals.cambridge.org 
her to invest in requisite means of xing. ${ }^{62}$ Reduced investment is rational because planning resources are finite. Planning for possible futures in which $\mathrm{C}$ is satisfied requires time and attention that might otherwise be spent planning for possible futures in which $\mathrm{C}$ is not satisfied, not to mention planning the rest of the agent's life or engaging in other worthwhile pursuits.

This is not to say that the agent's assessment of the probability of $\mathrm{C}$ alone determines how much it is rational to invest in the means of xing. As Ferrero observes, other relevant facts include the relative costs of preparing for $\mathrm{C}$ and not-C, the relative benefits A expects from realizing her intentions conditioned on $\mathrm{C}$ and from realizing her intentions conditioned on not-C, and A's attitude toward risk. ${ }^{63}$ That said, a person who has a foregroundconditional intention to $x$ only if $\mathrm{C}$ or to $x$ if and only if $\mathrm{C}$ should invest less in achieving the means of xing the less likely she considers $\mathrm{C}$ to be. A foreground condition on her intention is likely to reduce the "rational pressure for the addition of further intentions." 64

Finally, "planning and preparing for C" will often include adopting foreground-conditional intentions of the form:

$$
\text { A intends }\left(\text { not-C } \rightarrow_{\mathrm{F}} y\right)
$$

or:

$$
\text { A intends }\left(z \leftrightarrow_{\mathrm{F}}\right. \text { not-C). }
$$

These intentions, too, will be subject to pressures of means-end coherence, the force of which will, again, partly depend on the agent's assumptions

62. Yaffe makes a similar point. Yaffe, Conditional Intent, supra note 8, at 294.

63. Ferrero, supra note 10, \5.2.

64. Bratman, Intention, Plans, supra note 4, at 33. It is an interesting question how we should describe cases in which satisfaction of a necessary condition on an intention to $x$ is so unlikely that it reduces the rational pressure to intend necessary means of $x$ ing to the point where, given the costs, it is no longer rational to intend those means. Bratman suggests that in such cases, the agent no longer intends to $x$ :

Granted, my uncertainty about the efficaciousness of my plan for stopping at the bookstore might reasonably lead me not to bother with that plan, especially if I find the alternative path home nicer in other respects. But if I am persuaded by this then what I should do is give up on the intention to stop at the bookstore, not intend to stop there but still not intend known necessary means.

Bratman, Intention, Belief, supra note 13, at 32. But should we reach the same conclusion if there is no "alternative path"? Yaffe argues that "in this case, my conditional intention places me under rational pressure to adopt the means ... ; it is just that I am under stronger rational pressure not to decide on any action from which I can expect a loss." Yaffe, Conditional Intent, supra note 8 , at 294 . If the conditional intention still relaxes the consistency and agglomerativity constraints on the agent's deliberations, this seems right. If, however, the conditional intention does not relax those constraints, the agent has accepted the nonsatisfaction of the condition and the attitude is better characterized at most as a background-conditional intention.

\section{CAMBridge}

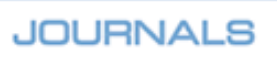

http://journals.cambridge.org 
about the probability of C..$^{65}$ Foreground necessary conditions on the agent's intention to $x$ can in this way take her in new directions, creating a rational pressure to adopt intentions that are not immediately related to and might be incompatible with xing.

\section{Summary}

The main components of the planning theory of conditional intentions can be summarized as follows. In our everyday talk we mark a difference between conditions whose nonoccurrence causes the agent to change her mind and those whose nonoccurrence does not. This intuitive distinction between background and foreground conditions can be explained by the effect of accepting satisfaction or nonsatisfaction of the condition, as distinguished from treating it as an open question, where "accepting" means taking something as given in one's practical deliberations. The fact that $\mathrm{C}$ is a foreground condition of A's intention to $x$ has on this theory two important consequences for A's ongoing deliberations and other undertakings. First, while consistency with an unconditional intention to $x$ restricts A's deliberations to plans co-realizable with xing, consistency with her foreground-conditional intention permits A to consider not-xing in the case of not- $\mathrm{C}$ and, depending on the whether her intention is strictly conditional, conditioned, or biconditional, perhaps other states of affairs as well. Second, if A's intention is foreground-conditional-and especially if it is foreground conditioned or biconditional-the lower A's evaluation is of the probability of $\mathrm{C}$, the less pressure means-end coherence creates to intend requisite means of xing. A background condition C on A's intention to $x$, on the contrary, has no such consequences for A's practical deliberations. It will, however, figure into the consistency constraint A's intention imposes on those deliberations.

This account explains both the intuitive plausibility of the awareness theory and where that theory goes wrong. When an agent treats the satisfaction of a condition on her intention as an open question, she is more likely to attend to it. Foreground conditions pose planning problems-what to do if the condition is not satisfied-that conscious deliberation can solve. But an agent might attend to a conditional intention even though she accepts that the condition is satisfied or nonsatisfied. Suppose Jones intends to expand the coffee shop and perform under the sales contract. If asked or if she is in a particularly reflective mood, Jones might allow that she will not perform if the space is condemned or if a Starbucks opens up across the street. She

65. Where the intention is foreground biconditional, the agent should also intend (not-C $\rightarrow_{\mathrm{F}}$ not- $x$ ). If not- $x$ ing takes some effort on the agent's part, means-end coherence will also require that the agent eventually intend the means of not-xing.

\section{CAmbridge}

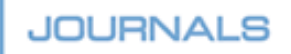

http://journals.cambridge.org 
would then be aware of these background conditions on her intention. But that theoretical awareness is unlikely to influence Jones's practical deliberations or actions. Because she accepts their satisfaction, it would be a waste of Jones's limited cognitive resources to plan for either contingency. Such reflective awareness of background conditions belongs to theoretical, not practical reasoning. ${ }^{66}$

\section{PROMISSORY REPRESENTATIONS OF INTENT}

I now turn to promissory representations of intent and the law's response to a promisor's undisclosed conditional intent to perform. I consider two related questions: When is a foreground condition on a promisor's intent to perform material? And what does a promise implicitly represent about such conditions and about the promisor's intent more generally? The analysis focuses on undisclosed necessary and necessary and sufficient conditions on a promisor's intent to perform. A promisor's strictly conditional intent to perform-her intent to perform if but not only if the condition is satisfiedis of less legal significance.

\section{A. Materiality: Foreground versus Background Conditions}

Recall Ayres's and my suggestion that a "promisor's intention to perform is material only because it entails her being likely to perform, only because

66. The above analysis has consequences for the proper analysis of generic ceteris paribus clauses, such as "provided that it is feasible" or "provided that it is advisable," which can be attached to any ascription of intention. Ferrero suggests that such generic qualifications should be included in a complete statement of the background conditions on a person's intention. Ferrero, supra note 10, $\mid$ \8.1-8.2. Translated into my notation, Ferrero would analyze A's foreground unconditional and background-conditional intention to $x$ as:

A intends $\left[\left(\mathrm{x} \rightarrow \rightarrow_{\mathrm{B}} \mathrm{P}_{1}, \mathrm{P}_{2} \ldots \mathrm{P}_{\mathrm{m}}, \& x\right.\right.$ is feasible $) \&\left(\mathrm{C}_{1}, \mathrm{C}_{2} \ldots \mathrm{C}_{\mathrm{q}}, \& x\right.$ is advisable $\left.\left.\rightarrow_{\mathrm{B}} x\right)\right]$,

where " $\mathrm{P}_{1}, \mathrm{P}_{2} \ldots \mathrm{P}_{\mathrm{m}}$ " stands for the complete list of "actually articulated" background enabling conditions on A's intent and " $\mathrm{C}_{1}, \mathrm{C}_{2} \ldots \mathrm{C}_{\mathrm{q}}$ " stands for the complete list of "actually articulated" background elective conditions on A's intent. (I take this to be a translation of Ferrero's (DS-E*) for a foreground unconditional intention; my parsing assumes that Ferrero's "GIVEN" operator is meant to describe necessary conditions when applied to enabling conditions and sufficient ones when applied to elective ones.) Ferrero stipulates that a condition on A's intent is "actually articulated" if A explicitly entertains it or might have entertained it at an earlier time or it is operative in A's psychology. Id. $₫$ 8.1. But once we have included in the analysis of A's intention to $x$ all of the background conditions that are operative in A's psychology, it is difficult to see what the generic feasibility or advisability conditions add to the analysis, not to mention conditions that $\mathrm{A}$ has or might have entertained but that are not operative, if such conditions could exist. For any potential condition $\mathrm{C}_{\mathrm{i}}\left(\right.$ or $\left.\mathrm{P}_{\mathrm{i}}\right)$ on A's intention to $x$, either A is rationally disposed to treat $\mathrm{C}_{\mathrm{i}}$ as a condition of her intention to $x$, or she is not. If $\mathrm{A}$ is so disposed, then $\mathrm{C}_{\mathrm{i}}$ is "operative" in A's psychology. If $\mathrm{A}$ is not so disposed, then the condition does not play a role in her practical reasoning. Ferrero says that the advisability placeholder is meant to capture the agent's acknowledgment of "yet unarticulated conditions that, if taken to obtain, would give her a good enough reason not to $\varphi$." Id. $\uparrow$ 8.5. But such an acknowledgment belongs to theoretical, not practical reasoning.

\section{CAmbridge}

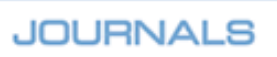

http://journals.cambridge.org 
it provides the promisee crucial information for evaluating [the probability of performance]." 67 On this picture, an undisclosed condition on the promisor's intent to perform is material when it reduces the likelihood of performance to a degree that, if it were known to the promisee, would affect the promisee's decision to enter into or otherwise invest in the transaction. Let $\mathrm{P}_{\mathrm{i}}$ stand for the mutually understood probability that the promisor will realize an unconditional intent to do the act promised, and $\alpha$ for the probability that an undisclosed intended necessary and sufficient condition for her performance will be satisfied. While the implicit representation that attaches to A's promise of an intent to perform says that the probability of performance is $\mathrm{P}_{\mathrm{i}}$, in fact the probability is $\alpha\left(\mathrm{P}_{\mathrm{i}}\right)$. At some point the difference between $\mathrm{P}_{\mathrm{i}}$ and $\alpha\left(\mathrm{P}_{\mathrm{i}}\right)$ will be so great that knowledge of the condition would affect the promisee's decision-making-he would reduce his investment in the deal, take additional precautions against nonperformance, or not enter into the transaction at all. This is the point at which the implicit representation of an unconditional intent to perform materially misrepresents the probability of performance and when an insincere promisor might be held legally liable for promissory fraud.

While this is correct as far as it goes, it is not the whole picture. As I argue in Section III, the above analysis cannot account for our intuitions about the difference between foreground and background conditions. The planning theory can. On the planning theory, background conditions on an agent's intention are those she accepts as satisfied, while foreground conditions are those whose satisfaction she treats as an open question. There are three reasons on this theory to expect a foreground condition on a promisor's intent to perform to be material, though a background condition with the same content would not be: the foreground condition is likely to affect the promisor's preperformance deliberations and behavior in a way that further reduces the likelihood of performance; the fact that the promisor has not accepted satisfaction of the condition for the purposes of her own practical deliberations is evidence that the promisee should also to take the possibility into account; and a foreground condition is more likely to prevent the parties from filling contract gaps in a mutually satisfactory way.

At this point, let me drop Jones's hypothetical coffee shop and use as an example the facts described by the Hawaii Supreme Court in Chung $v$. Kaonohi Center Co. ${ }^{68}$ In January 1972, the Chung plaintiffs signed with the defendants a ten-year lease for a food concession space in a mall that the

67. AYREs \& KLASS, supra note 3 , at 35.

68. Chung v. Kaonohi Center Co., 618 P.2d 283 (Haw. 1980). Chung affirmed an emotional distress award based on a tort theory of wanton or reckless conduct in the breach. The Hawaiian court has since rejected that rule, abrogating the holding in Chung, and ruled that emotional damages are available only when the defendant's behavior violates an independent tort-based duty. Francis v. Lee Enters., Inc., 971 P.2d 707, 717 (Haw. 1999). But as Ayres and I argue, the Chung defendants' behavior looks like it also satisfies the elements of promissory fraud, which would support the award of punitive damages in the case even under the new rule. AYRES \& KLASS, supra note 3, at 28.

\section{CAmbridge}

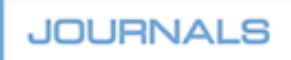

http://journals.cambridge.org 
defendants were building. After the parties signed the lease, the "plaintiffs arranged for financing, ordered equipment and furnishings, hired chefs and workers, advertised in the yellow pages of the telephone book for the to-be-built kitchen, and incurred other expenses." ${ }^{69}$ Though the defendants were aware of the plaintiffs' investments, they continued to offer the space to other potential tenants. Eventually the defendants signed another, presumably more profitable, lease for the space and in June 1973 informed the plaintiffs that it was no longer available.

The Chung defendants' postformation behavior is strong evidence that their intent to perform was foreground conditioned or biconditionalthat the defendants intended to perform their promise to lease only if, or if and only if, they did not find another, more profitable tenant. But the defendants' continued negotiations with other tenants were not only evidence of an undisclosed condition on their intent to perform; from the plaintiffs' perspective, those negotiations were also part of the problem with the undisclosed condition. The foreground condition did not decrease the probability of performance by some fixed probability, as " $\alpha\left(\mathrm{P}_{\mathrm{i}}\right)$ " might suggest. It also affected the defendants' attitudes and actions prior to the time of performance in a way that further reduced the chance they would perform. ${ }^{70}$ Most obviously on the facts of the case, the foreground condition relaxed the consistency constraint that an unconditional intent to perform or a background conditioned intent would otherwise impose, permitting the defendants rationally to pursue plans, like leasing the space to someone else, incompatible with performance. Such alternative planning worked to decrease the chances that the condition would be satisfied-that is, it reduced $\alpha$. Here we see an advantage of the truth-functional reading of conditional intentions. The Chung defendants worked to realize their foreground biconditional intention by preventing satisfaction of the condition.

Chung is perhaps unusual, as the satisfaction of the condition was partly in the defendant's control. But even where this is not the case, or where the defendant has independent reasons to prefer the condition's satisfaction, a foreground necessary condition is still likely to affect her planning and the resources she invests in performing. As I argue in Section III, the fact that a person's intent to $x$ is foreground conditioned or biconditional reduces the rational pressure to adopt necessary means of xing. Recall the Hillcrest case, in which the defendant did not disclose that she intended to purchase a neighboring property for parking only if she found a tenant for it. ${ }^{71}$ Even if we assume that the defendant made every effort to find a tenant for the property, the undisclosed condition reduced the rational pressure on her to

69. Chung, supra note 68 , at 286.

70. Bratman makes a related point: "the dispositions to figure out how to do what one intends, and to settle on needed preliminary steps, provide support for the expectation that an agent will both be in a position to do what she intends and succeed in doing it." BRATMAN, InTENTION, Plans, supra note 4, at 18.

71. Hillcrest, supra note 1 .

\section{CAMBRIDGE}

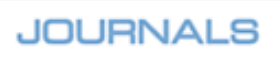

http://journals.cambridge.org 
take other steps necessary to purchasing it-to contact the owners, to secure funds for the purchase, to put down a nonrefundable deposit, and so forth. Such decreased investment in performance further reduces the probability of performance-now not by reducing $\alpha$ but by reducing the chances that the promisor will be able to perform if the condition is satisfied, or reducing $\mathrm{P}_{\mathrm{i}}$.

These consequences would not have attached if the Chung or Hillcrest defendants' intent to perform had been background biconditional. If the Chung defendants had accepted that they would not find a more profitable tenant-if they had taken it as given in their practical deliberations that the condition on their intention to perform would be satisfied-consistency would have prevented them from seeking out other tenants, and means-end coherence would have required them to invest in planning for performance as if their intent to perform were unconditional. If the Hillcrest defendant had taken it as given that she would find a tenant for the neighboring property, means-end coherence would have required the same investments in preparing to purchase as an unconditional intent to purchase would have.

A second reason foreground conditions on a promisor's intent to perform are much more likely to be material follows from the fact that the promisor has not accepted the condition in her own deliberations. A promisor's acceptance of a condition $\mathrm{C}$ on her intent to perform means that she takes $\mathrm{C}$ as given in her practical deliberations, though on reflection or when considering other practical problems, she might recognize the possibility of not-C. An agent's acceptance of a condition is often based on an informal and unreflective cost-benefit analysis. It is rational to accept $\mathrm{C}$ for the purposes of one's practical deliberations when, given what one knows, $\mathrm{C}$ is so likely true that the risk-adjusted benefits of planning for not-C are not worth its cognitive-resource costs. ${ }^{72}$ When considering whether to ride my bike to campus, it is rational for me to assume it will get me there. The chance that it will not is so low that it is not worth the time or effort to consider. But if I know that my chain has been slipping and the derailleur sticking, it might be worth taking that possibility into account. That an agent treats $\mathrm{C}$ as an open question suggests a (perhaps reflexive) judgment on her part that the chances of not-C are so high that it is worth the time and effort to plan for that contingency.

72. I take this to be implicit in Bratman's description of simplification. BRATMAN, Practical Reasoning, supra note 35, at 21-22. Compare Bratman's description of the cost-benefit analysis involved in when it is rational to reconsider one's intentions. BRATMAN, INTENTION, Plans, supra note 4 , at $64-70$.

Bratman suggests a number of other possible reasons for acceptance, including special relations with others. BRATMAN, Practical Reasoning, supra note 35, at 25. Some contractual promises-those that establish a moral relationship between the parties-might create the sort of special relation that makes it rational for the promisor to deliberate as if her conditional intent to perform were unconditional.

\section{CAMBRIDGE}

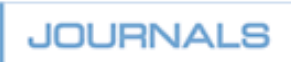

http://journals.cambridge.org 
Such a judgment by a promisor with respect to a condition on her intent to perform would be of obvious interest to the promisee. ${ }^{73}$ This is again illustrated by the facts in Chung. If the Chung defendants' intention to lease the space to the plaintiffs was foreground-conditional on not finding a better tenant, that was because they considered the probability of finding another tenant high enough that it was worth taking that possibility into account in their practical deliberations. That fact alone-apart from the condition's effect on the defendants' preperformance deliberations and actions-suggests that the plaintiffs would also have wanted to take it into account. Knowledge of the condition would also have affected the plaintiffs' deliberations about how much to invest in the transaction. This logic would not apply if the defendants' intent to lease had been merely background conditioned on there being no better offer for the space. In that case, the defendants themselves would have made a judgment that the probability of a better deal was so low that it was not worth planning for that contingency, suggesting that the plaintiffs need not worry about it either.

A final reason we should expect foreground conditions to be material involves Bratman's concept of shared intentions. My discussion of Bratman's planning theory has so far emphasized the intrapersonal function of futureoriented intentions: intentions organize an individual's deliberations and actions over time, allowing her to settle on and effectively pursue objectives that require temporally extended planning and execution. Intentions also enable complex interpersonal coordination. One way is obvious: B's knowledge that A intends to $x$ often supports a prediction that A will $x$, which permits B to coordinate his behavior with A's. ${ }^{74}$ But that is not all. Bratman's theory of shared intentions extends his planning theory to describe the distinctive attitudes of persons engaged in shared projects, such as painting a house together or singing a duet. ${ }^{75}$ The technical details of the theory are relatively complex, and its application to contractual agreements raises issues beyond the central themes of this article. But I hope at least to indicate how the role of shared intentions in many contractual agreements provides a third reason to care especially about foreground conditions on a promisor's intent to perform.

It is common wisdom among contract theorists today that parties' contractual obligations-their legal duties-often do not map onto their reasonable expectations of one another. ${ }^{76}$ In Karl Llewellyn's words, there is a

73. This is especially the case where the promisor knows more than the promisee about the likely satisfaction of the condition. It is therefore relevant that the Chung defendants were in the business of leasing such properties and therefore probably knew more than the plaintiffs about the chances that a more profitable tenant would come along.

74. See Bratman, Intention, Plans, supra note 4, at 37.

75. Michael E. Bratman, Shared Cooperative Activity, 101 PhIL. Rev. 327 (1992), reprinted in FACES of Intention: Selected EsSAys on Intention AND AgENCy 93 (1999); Michael E. BRATMAN, Shared Intention, 104 ETHICs 97 (1993), reprinted in FACES OF INTENTION: SELECTED EsSAYS ON INTENTION AND AGENCY 109 (1999).

76. As Robert Scott says, "[w]e are all relationalists now." Scott, supra note 11, at 852.

\section{CAMBridge}

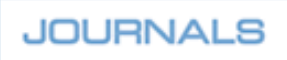

http://journals.cambridge.org 
"difference in content between the running, flexible obligation understood in fact by the parties and the rigid, stereotyped obligation which is all the law will recognize." ${ }^{77}$ For example, while a commercial lease might impose a variety of detailed obligations on the parties-permitted use of the space, how it will be fitted out, maintenance, security, insurance, and so forth-other aspects of their relationship will be left to future agreement, negotiation, or bargaining. One reason parties can rationally leave such matters undecided is that each typically has evidence that the other is committed to the transaction. To take a trivial example, suppose the Chung lease required the defendant-owners to paint the space but did not specify a color. ${ }^{78}$ Suppose further (perhaps contrary to fact) that a court would read the lease as permitting the owners to use any color they chose. The tenants might sign such a lease with a reasonable expectation that the owners would consult with them on the color despite not having a legal obligation to do so. Assuming that the owners intended to go through with the transaction, the owners would also be interested in the success of the tenants' venture, which would have positive spillover effects for the mall as a whole. And because the owners are committed to the transaction, they have a general interest in the tenants' continued participation in it and so in the tenants' satisfaction.

We can generalize from this example and translate it into Bratman's theory of shared intentions as follows. Relational contracts are not simply exchanges of unilateral promises but involve agreements to engage in joint intentional or shared cooperative activities-"shared projects" for short. ${ }^{79}$ These can be as simple as having someone fix a bicycle or as complex as a long-term management agreement. As with other intentions, each party's intent to take part in the shared project creates a rational pressure further to intend and undertake the necessary means of realizing that project. But unlike nonshared intentions, because each intends the activity as a shared project, each is further committed to intending means that are consistent with the means intended by the other. As Bratman puts it, they are committed to meshing subplans. When the means of realizing the joint project are not specified in advance (as in a contract), the commitment to engage in the shared project imposes a rational pressure to reach agreement on them. Each party's commitment to the shared project therefore underwrites a prediction that they will be able to fill gaps in their original plan in a way generally satisfactory to both.

77. Karl N. Llewellyn, What Price Contract? - An Essay in Perspective, 40 Yale L.J. 704, 712-713 (1931). The two classic modern works in the field are Stewart Macaulay, Non-Contractual Relations in Business: A Preliminary Study, 28 Am. Soc. Rev. 55 (1963); and Ian Macneil, Contracts: Adjustment of Long-Term Economic Relations under Classical, Neoclassical, and Relational Contract Law, 72 Nw. U. L. Rev. 854 (1978).

78. The example is adapted from Bratman. See Bratman, Cooperative Activity, supra note 75, at $98-99$.

79. For the difference between joint intentional and shared cooperative activities, see Scott J. Shapiro, Law, Plans, and Practical Reason, 8 Legal Theory 387, 394-401 (2002).

\section{CAMBRIDGE}

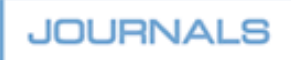

http://journals.cambridge.org 
While there is more to be said about the details of this picture,$^{80}$ this is enough to identify the negative relational consequences of an undisclosed foreground condition on one party's intent to complete the transaction. Just as a conditional intent to perform reduces the rational pressure to intend means of performing and permits the promisor to plan rationally for her breach, so in a relational contract a foreground condition will reduce the pressure to arrive at mutually acceptable approaches to as-yet-unspecified details of the transaction. The Chung defendants' foreground-conditional intent to perform made it all the more likely that they would conform to the letter of the lease (in the imagined case, painting the space) without attending to its spirit (choosing a color that worked with the plaintiffs' planned use). In extreme cases of unilateral, self-interested exercises of contractual discretion, a promisor risks liability for breach of the duty of good faith. Between those extreme cases and collaborative gap-filling lies a range of uncooperative behavior that denies the other party some reasonably expected benefit without breaching the contract. An undisclosed foreground condition (but not a background condition) to perform makes it all the more likely that the promisor's behavior will tend toward the unilateral and uncooperative end of that range, depriving the promisee of benefits she reasonably expects even if the promisor ultimately performs.

In sum, the planning theory of conditional intentions explains as follows the legal relevance of foreground and background necessary conditions on a promisor's intent to perform. Both foreground and background conditions on that intention impact the probability of performance. An intent to $x$ only if, or if and only if, $\mathrm{C}$ means that the probability that the agent will $x$ depends in part on the likelihood of $\mathrm{C}$, whether or not the promisor accepts $\mathrm{C}$ in her practical deliberations. The promisor's nonacceptance of $\mathrm{C}$, however, has several important consequences. For one thing, it means that she perceives the chances of not-C as high enough to warrant taking that possibility into account in her own practical deliberations. This suggests that the promisee might also want to take into account the possibility of not-C and its impact on the promisor's performance. In addition, the promisor's nonacceptance of a condition on her performance can affect her deliberations and preperformance behavior in ways that harm the promisee. She is more likely to continue planning for possible futures in which she does not perform

80. More, for example, about the degree of cooperation, about the extent to which the parties' plans must mesh, and about the nature of the shared project. Any thinking about the degree of cooperation in contractual relationships should take account of Shapiro's work on shared intentions in institutional, authority-based structures. Id. passim. With respect to the nature of the shared project, the above description purposively leaves room for a thicker account of shared projects than Daniel Markovits's description of contractual exchanges as joint intentional activities arising out of relatively thin promissory commitments. Daniel Markovits, Contract and Collaboration, 113 Yale L.J. 1417, 1456-1463 (2003); see Gregory Klass, Three Pictures of Contract: Power, Duty and Compound Rule, 83 N.Y.U. L. REv. 1726, 1747-1750 (2008) (suggesting an alternative description).

\section{CAMBridge}

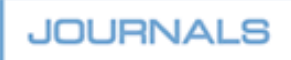

http://journals.cambridge.org 
and less likely to invest in securing the means of performance. And a foreground condition on a promisor's intent to perform reduces the rational pressure on her to fill contract gaps in ways that mesh with the promisee's plans and preferences. None of these consequence attaches to background conditions on a promisor's intent to perform.

\section{B. What a Promise Says}

Both Richard Craswell and Aditi Bagchi suggest that on Ayres's and my theory, the law might dispense with promissory representations of intent and focus solely on what a promise says about the probability of performance. Craswell advocates such a rule. He worries that a focus on the promisor's intent "too easily slide[s] into a binary inquiry: Either the defendant intended to perform, or she didn't." ${ }^{81}$ Starting from our suggestion that a promisor's intentions are material only because of what they tell the promisee about the probability of performance, Craswell argues:

as long as the probability of performance is what is material to customers, that is the variable that will normally carry most of the weight, both in assessing potential costs and in assessing potential benefits. Parties' intentions, by contrast, will be relevant (in a cost-benefit analysis) only for what they tell us about the costs and benefits of the more material variables. ${ }^{82}$

Bagchi reaches the same conclusion about the implications of our analysis, though she is more critical of them. ${ }^{83}$ On her view, our approach neglects the special moral problems with lying promises and therefore is incomplete as an account of the law of promissory fraud. A concept of promisor intent that is no more than a placeholder for the probability of performance "is a hollow one, and it would empty the doctrine of promissory fraud of much of its moral import-or, it would empty it of all the moral force associated with voluntary commitment and its breach." 84

I think neither of these criticisms hits the mark, even assuming the relatively impoverished concept of intent that Ayres and I employ. From a strictly consequentialist perspective, there would be reasons for the law to focus on promisor intent even if all that mattered were the probability of performance. The representation of an intent to perform is an integral

81. Richard Craswell, Taking Information Seriously: Misrepresentation and Nondisclosure in Contract Law and Elsewhere, 92 VA. L. REV. 565, 628 (2006).

82. Id. at 629 .

83. " $[\mathrm{I}] \mathrm{n}$ Ayres and Klass's strictly economic account, this subjective intent is drained of any agent particularity. As such, Ayres and Klass could do well enough without the complicating notion of intent. ... It would be cleaner to speak of the probability of performance in purely objective terms without alluding to choice." Aditi Bagchi, The Accidental Promise: Remaking the Law of Misrepresented Intent, 2008 U. ILL. L. REV. 985, 992; see also id. at 1002, 1006-1007.

84. Id. at 1007.

\section{CAMBRIDGE}

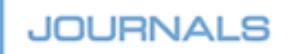

http://journals.cambridge.org 
part of the extralegal practice of entering into an agreement-not because it provides information about the probability of performance, but because an intent to perform is, to use John Searle's phrase, among the normal "felicity conditions" of undertaking a voluntary obligation. ${ }^{85}$ That representation of intent, while not as informative or fine-grained as a representation of the probability of performance, is cheap to include, easy to understand, and usually gives the promisee all the information he needs as to the probability of performance. By the same token, framing the question in terms of the promisor's intent serves a valuable heuristic function in an ex post evaluation of whether there was a material misrepresentation. While courts should be sensitive to the fact that intent is not all that is material, it would be wrong to jettison it from the legal inquiry. I would also take issue with Bagchi's characterization of our attitude as purely consequentialist and her assumption that we have an "objection" to moral theories of the law of promissory misrepresentation. ${ }^{86}$ Our argument focuses on consequentialist legal arguments because in our view the results of that analysis are the more surprising ones, not because we believe deontological arguments had no place in legal reasoning. ${ }^{87}$

That said, Craswell's and Bagchi's readings make a certain amount of sense given the anemic concept of intention we employ in the book. The above, more robust concept suggests deeper, though still consequentialist, reasons why the law should attend to the promisor's intent to perform. Contrary to our assumption in Insincere Promises, promissory representations of intent are material not only because they say something about the probability of performance but because they provide important information about the promisor's likely attitudes and actions in the time leading up to performance. Especially in relational contracts in which the parties rely on nonlegal norms and other incentives, a promissory representation of intent says as much about the value of the transaction as a whole as about the probability of performance. In such transactions, the promisor's lack of an intent to perform can prevent her from acting in ways that are not required by the contract but would benefit the promisee. The richer conception of intent also figures into the moral reasons for holding insincere promisors legally liable that concern Bagchi.

The planning theory also suggests refinements to Ayres's and my analysis of the representational content of contractual promises. As noted above, promissory representations of intent often occur against a shared understanding of conditions under which the promisor might choose not to

85. John R. Searle, Speech Acts: An Essay in the Philosophy of Language 54-63 (1969); see also AYREs \& KLASS, supra note 3, at 29 (describing moral basis for promissory representations). If this is right, the bare representation of an intent to perform is neither a conversational implicature nor a conventional one. See Stephen C. Levinson, Pragmatics 126-132 (1983) (describing the distinction between conversational and conventional implicature).

86. Bagchi, supra note 83, at 1005 n. 83.

87. See AYres \& KLASS, supra note 3, at 61.

\section{Cambridge}

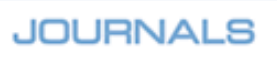

http://journals.cambridge.org 
perform or be prevented from doing so. That "background" understanding should not be confused with the background conditions on the promisor's intent to perform. Background conditions qualify as such by virtue of their role in the promisor's practical reasoning, not the promisee's knowledge of them. And while the parties might have a shared understanding of what those background conditions are likely to be, we should not be too quick to assume that the act of promising says anything about them.

This is so because the implicit content of a speech act depends in part on the objective importance of the information in question. ${ }^{88}$ For all the reasons discussed above, the background conditions on a promisor's intent to perform are normally not material. They are relatively unimportant. While the details are complex, this suggests that an unconditional promise represents an unconditional intent to perform, not an intent to perform in certain mutually understood and accepted circumstances. ${ }^{89}$ This is so despite the fact that both parties should understand that an intent to perform is not an intent to perform come what may; that is, that the promisor's intent to perform will naturally be background-conditional. Because a foreground condition on the promisor's intent to perform is much more likely to be of importance to the promisee, conversational norms require that a promisor with a foreground-conditional intent qualify the otherwise implicit promissory representation. ${ }^{90}$

Another way of putting the above point is to say that a contractual promise does not, as such, represent anything about the promisor's character-about her dispositions to perform or breach in circumstances that while they may be theoretically possible, she does not consider practically relevant. What a promise normally does represent is the promisor's present practical attitude toward performance: that she intends to perform and, by implication, that she presently accepts the satisfaction of any conditions on that intent. The promise represents that the promisor's intent to perform is not foregroundconditional, although, like all intentions, it will be subject to an indefinite number of background conditions.

\section{CONCLUSION}

An intent to perform is not like a billiard ball that the promisor puts in motion and which then continues in a straight line until it is withdrawn,

\footnotetext{
88. For a brief account of this Gricean point, see Craswell, supra note 81, at 601-05. See generally PAUL GRICE, Logic and Conversation, in STUDIES IN THE WAY OF WORDS 22 (1989); GRICE, Further Notes on Logic and Conversation, in STUDIES IN THE WAY OF WORDS 50 (1989).

89. The above argument is very abbreviated. One would want to say more, for example, about just how Grice's cooperation principle and the rules of conversational implicature interact with the implicit representation of an intent to perform, which, as I observe above, supra note 85 , is not a product of conversational implicature.

90. Such a qualification would be required, for example, by Grice's first maxim of quantity: "Make your contribution as informative as is required (for the current purposes of the exchange)." GRICE, Logic and Conversation, supra note 88, at 26.
}

\section{CAMBRIDGE}

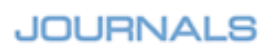

http://journals.cambridge.org 
blocked, or realized. A promisor's intent with respect to performance structures her deliberations and behavior along the way, and the promisee might reasonably care as much about those intervening effects as about the bare likelihood of performance. A promisor's intent with respect to performance is material not only because it says something about the probability of her performance but also because it is crucial information about her attitude toward the transaction as a whole. 